\title{
Asymmetric Information and Annuities
}

\author{
Silvia Platoni \\ Royal Holloway, University of London, Egham, Surrey TW20 0EX, UK \\ Università Cattolica, via Emilia Parmense 84, 29100, Piacenza, Italy
}

\begin{abstract}
The standard Rothschild and Stiglitz (1976) and Wilson (1977) analysis of adverse selection economies is extended to a particular model of annuity market which features both elements of moral hazard and adverse selection. Individuals are heterogeneous with respect to time preferences and they make investments in health care that affect their survival probabilities. The main case considered is that where both preferences and investments (and hence the endogenous survival probabilities) are unobserved. Thus the model captures a further source of inefficiency that is particular to annuity market: an endogenous correlation between the desire for annuities and the survival probabilities. The basic insights of Wilson (1977) - as worked out by Eckstein, Eichenbaum and Peled (1985) - are worth also in this new setting. When the equilibrium is separating, the government intervention may yield Pareto improvements. If the equilibrium is pooling, the government intervention may improve the well-being of individuals affected by the inefficiencies and the negative externalities caused by the asymmetric information.
\end{abstract}

JEL classification: $\mathrm{H} 23 ; \mathrm{H} 42 ; \mathrm{D} 82$

Keywords: Annuities; Asymmetric; Private Information

\section{Introduction}

According to Diamond (1977) there are four reasons for a social security programme: income redistribution, market failure, paternalism and efficiency. However, a considerable number of interventions in the programmes of health insurance, unemployment insurance, disability insurance and public pensions - insurance against longevity - in Western democracies must be considered not as a remedy for any of the classical market failures, nor as an efficient device for redistribution, but as a consequence of asymmetric information (see, e.g., Anderberg (1999)).

Several authors (see, e.g., Rothschild and Stiglitz (1976), Wilson (1977), Riley (1979a), Riley (1979b) and Eckstein, Eichenbaum and Peled (1985)) have analysed the case in which individuals possess hidden information about 
their longevity, that is when there is adverse selection in the annuity market and a group of individuals (individuals with lower survival probability) is affected by negative externalities.

Among many recent developments in the economics of information, one of the most controversial has been the development of the notion of an informational equilibrium. This is an equilibrium in a world of incomplete markets, where either the observed actions of better-informed agents or the resulting equilibrium prices yield valuable information to worse-informed agents (see, e.g., Riley (1979a)).

Rothschild and Stiglitz (1976) have considered firms that accomplish a screening strategy and they have defined an equilibrium as a set of contracts such that when agents choose contract to maximize their expected utility (i) no contract in the equilibrium set makes negative expected profits and (ii) there is no contract outside the equilibrium set that, if offered, will make a nonnegative profit. Given these basic features of the equilibrium, in a RothschildStiglitz equilibrium each firm assumes that the contract its competitors offer are independent of its own actions - Nash-Cournot type equilibrium. Then each contract offered in equilibrium earns zero profits: positive profits on any single contract are eliminated by the undercutting process carried out among the firms and cross-subsidization among different contracts offered by any given firm can be rule out by noting that firms will withdraw contracts that persistently yield negative profits (see, e.g., Rothschild and Stiglitz (1976) and Eckstein, Eichenbaum and Peled (1985)).

However, a Rothschild-Stiglitz equilibrium has problems of non-existence (see Appendix): (i) there cannot be a Rothschild-Stiglitz pooling equilibrium and (ii) consequently if there is a relatively small number of agents with higher survival probability there does not exist a Rothschild-Stiglitz equilibrium (see, e.g., Wilson (1977), Riley (1979b) and Eckstein, Eichenbaum and Peled (1985)).

Wilson (1977) has solved the problems of non-existence of a RothschildStiglitz equilibrium in a contest in which firms carry on accomplishing a screening strategy: each firm will correctly anticipate which of those policies that are offered by other firms will become unprofitable as a consequence of any change in its own policies. Then a firm offers a new policy only if it makes non-negative profits after all the other firms have made the expected adjustment in their policy offers (see, e.g., Wilson (1977) and Eckstein, Eichenbaum and Peled (1985)).

Riley (1979b) has solved the problems of non-existence of a RothschildStiglitz equilibrium in a context in which firms adopt a signalling strategy: sellers of higher quality products can adopt activities that operate as a "signal" to potential buyers ${ }^{1}$.

$\overline{1}$ For example (i) the fly-by-night operator faces a higher advertising cost per unit of sales than the new entrant who plans to build and then maintain his reputation, (ii) in the labour market productivity on the job is positively correlated with per- 
As is well-known, in the presence of asymmetric information, the competitive equilibrium generally fails to achieve a first-best allocation. Hence there are potentially scopes for Pareto improvements, and it becomes interesting to consider whether any such improvements can be obtained through government intervention.

Eckstein, Eichenbaum and Peled (1985) have argued that a mandatory social security programme undertaken by a Social Planner can have positive effects on welfare when the annuity market is affected by adverse selection: an initial pooling equilibrium can always be Pareto dominated by a public programme, while an initial separating equilibrium dominates or is dominated by such a programme.

These results hold on the assumption that individuals are restricted to purchasing only one private insurance policy. In fact Finkelstein (2002) has shown that the Pareto improving role for the government derives not from its unique capacity to compel participation in a public insurance programme, but from the fact that individuals may hold multiple insurance policies - one public and one private.

Shavell (1979) and Davies and Kuhn (1992) have analysed the tendency of insurance protection to alter an individual's motive to prevent loss. In particular Davies and Kuhn (1992) have explored the case in which individuals can take hidden actions to affect their longevity by consuming "health-related goods", that is when there is moral hazard in the annuity market and all individuals are affected by inefficiencies. They have shown that social security never raises welfare in a pure moral hazard economy.

Pauly (1974) has underlined the effects of both asymmetric information types on the provision of insurance. Hence in this work we consider the case in which the annuity market is troubled by both adverse selection (individuals possess hidden information about their longevity) and moral hazard (individuals can take hidden actions to affect their longevity).

The paper proceeds as follows. In Section 2 we describe the setup of the model. While in Section 3 we present the competitive equilibrium with public information, in Section 4 we consider the case of private information regarding the investments in health care (moral hazard) or/and the individual types (adverse selection). In Section 5 we investigate the possible Pareto improving policies which the Social Planner can implement. Finally Section 6 concludes.

\section{The Model}

The model to be studied is an extension of the Rothschild and Stiglitz (1976) and Wilson (1977) analysis. In this economy there is a single non-storable

formance in school and therefore the higher productivity worker has on average a lower personal cost of obtaining a given set of educational credentials and (iii) in purchasing insurance the marginal cost of accepting a higher coinsurance rate for a specific loss is lower for those with a lower probability of loss (see Riley (1979b)). 
and non-producible consumption good $c$ and the interest rate is $r=0$. Each young agent is endowed at birth with $\omega$ units of the consumption good. All individuals live for a maximum of two periods $(t=1,2)$ : each individual is alive for certain in the first period and survives with some probability $\pi$ into the second period.

\subsection{Basic Structure}

If we consider the health care as "capabilities and mechanism of defense that protect an organism from external stress" (see, e.g., Correa (1983)), an individual can increase his survival probability into the second period by investing in health care in the first period: an individual survives with probability $\pi(h)$ into the second period, where $h$ represents the investment level in health care in the first period (see, e.g., Davies and Kuhn (1992)). The function $\pi(h)$ is assumed linear: with $p$ the price of a unit of investment in health care $h$ and

by setting $h^{\max }=\frac{\omega}{p}$ the maximum feasible investment in $h$, an individual survives with probability

$$
\pi(h)=\frac{h}{h^{\max }}=\frac{p \cdot h}{\omega}
$$

into the second period, with $0 \leq \pi(h) \leq 1, \pi(h) \longrightarrow 0$ as $h \longrightarrow 0, \pi(h) \longrightarrow 1$ as $h \longrightarrow h^{\max }$ and

$$
\pi^{\prime}=\frac{p}{\omega}
$$

The cost of investing in a level of health care $h$ is given by the linear function

$$
c(h)=p \cdot h
$$

with

$$
c^{\prime}=p
$$

Davies and Kuhn (1992), Epple and Romano (1996) and Gouveia (1997) consider $h$ as a good (and not as an investment). With $h$ as a good the utility in the first period would be given by the utility function $u\left(c_{1}, h\right)$ over $c_{1}$ and $h$.

Moreover while Davies and Kuhn (1992) consider the category doctors as a "bad" 2 , Epple and Romano (1996) and Gouveia (1997) consider the health care as a "normal good". The lack of a univocal view in the literature (and the possibility to simplify the analysis) suggests to consider the expenditure in health care as an investment that doesn't affect the utility in the first period, but the budget constraint and the survival probability into the second period.

2 Individuals can affect their survival probability by consuming health-related goods, categorized into three types, labelled "cigarettes" with $u_{c}^{\prime}>0$ and $\pi_{c}^{\prime}<0$, "nutrition" with $u_{n}^{\prime}>0$ and $\pi_{n}^{\prime}>0$ and "doctors" with $u_{d}^{\prime} \leq 0$ and $\pi_{d}^{\prime}>0$ (see Davies and Kuhn (1992)). 
In this paper we consider a case where there is heterogeneity with respect to preferences: this primitive heterogeneity is translated, through investments in health care, into endogenous heterogeneity in survival probabilities.

We suppose the population is partitioned into two distinct groups, $L$ and $H$, whose relative size is fixed, so that for each agent of type $L$ there are $\gamma$ agents of type $H$, with $\gamma>0$ (see, e.g., Eckstein, Eichenbaum and Peled (1985)). Individuals of two groups are heterogeneous in time preference: consumers discount the future placing different weight upon it. In particular we assume that members of group $H$ care more about the future than members of group $L$. Then if we define $\beta^{i}$ with $0 \leq \beta^{i} \leq 1(i=L, H)$ the rate of time preference we have

$$
\beta^{L}<\beta^{H}
$$

Hence the representative individual's expected lifetime utility is given by

$$
U^{i}=u\left(c_{1}^{i}\right)+\beta^{i} \pi\left(h^{i}\right) u\left(c_{2}^{i}\right), i=L, H
$$

where $u^{\prime}(c)>0, u^{\prime \prime}(c)<0, u^{\prime}(c) \longrightarrow \infty$ as $c \longrightarrow 0$ and $u^{\prime}(c) \longrightarrow 0$ as $c \longrightarrow \infty$ and the individuals' consumption sets are bounded by $0 \leq h^{i} \leq h^{\max }$ 3 .

Therefore we have described the two important features whose combination distinguishes this model from the previous literature. The investment in health care $h$ (whose set is continuum) is a choice variable and the moral hazard problem occurs when this choice is unobservable. Individuals are heterogeneous in time preference $\beta$ and the adverse selection problem relies on $\beta$ being a private information. Hence both the adverse selection problem and the moral hazard problem arise from endogenous factors ${ }^{4}$.

Agents allocate consumption intertemporally by purchasing annuities which are supplied by competitive firms that diversify risk using the fact that survival outcomes are not correlated across individuals. An annuity bond at period $t$ is a claim to a certain quantity of the consumption good at period $t+1$ which is payable only if the original purchaser of the annuity is alive. Normalizing the purchasing price of a period $t$ annuity to one unit of the good at $t$, the annuity's rate of return represents the intertemporal terms of trade faced by its buyer.

Then we define an annuity contract as a two dimensional vector $(s, R)$ with $s$ premium and $R$ gross rate of return - so that if a young agent purchase this contract his consumption vector $\left(c_{1}, c_{2}\right)$ becomes $(\omega-c(h)-s, s \cdot R)$ if he lives two periods and $(\omega-c(h)-s, 0)$ if he lives only one period. We assume

$\overline{3}$ In the following we will focus on the case where the inequality constraints $0 \leq$ $h^{i} \leq h^{\max }$ are not binding.

4 With regard to the adverse selection problem, in Rothschild and Stiglitz (1976), Wilson (1977) and Eckstein, Eichenbaum and Peled (1985) the heterogeneous survival probabilities $\pi^{L}$ and $\pi^{H}$ are exogenously assumed. 
$s \geq 0^{5}$ - the consumer cannot sell off the future income for most first period income.

Given the heterogeneity of the population with respect to the rate of time preference $\beta$, we can think of two kinds of annuity equilibrium: (i) a separating equilibrium in which agents with different rate of time preference - survival probability - purchase annuities with different rate of return and (ii) a pooling equilibrium in which the same annuity is purchased by members of different groups.

If we assume that the population size is large, the survival probabilities are also the proportions of each type that live for the second period. Since the relative size of the two groups is fixed, there is absence of aggregate uncertainty regarding the number of deaths in each group and then absence of uncertainty regarding the profits of the annuity supplying firms. Therefore in either a separating or pooling equilibrium real profits must be equal to zero.

Because of the problem of non-existence of a Rothschild-Stiglitz equilibrium (see Appendix) in the following analysis we will consider a Wilson equilibrium (see, e.g., Wilson (1977) and Eckstein, Eichenbaum and Peled (1985)).

We will clarify the results by presenting a computational model ${ }^{1}$ where the parameterisation is chosen mainly for numerical convenience: we will assume that preferences are given by a logarithmic utility function, the endowed income is $\omega=1000$ and the price of a unit of investment in health care is $p=1.25$.

\subsection{Contracts}

The contract $\left(s^{i}, R^{i}\right)$ will be actuarially fair for individual type $i$ when it breaks even given the action $h^{i}$ taken by this type; this requires that for each individual type $i$ the premium should equal the expected payout

$$
s^{i}=\pi\left(h^{i}\right) s^{i} R^{i}, i=L, H
$$

Hence, the actuarial fairness condition can be summarized as

$$
R\left(h^{i}\right)=\frac{1}{\pi\left(h^{i}\right)}, i=L, H
$$

For most of the analysis we will phrase the discussion in terms of the net endowment that a given contract induces. In fact a given contract determines two quantities

$$
\begin{aligned}
& x_{1}=\omega-s \\
& x_{2}=s \cdot R
\end{aligned}
$$

\footnotetext{
$\overline{5}$ In the following we will focus on the case where the inequality constraint $s \geq 0$ is not binding.

1 The simulations are made with GAUSS programme.
} 
where $x_{1}$ are the net resources available to the individual after paying the premium $s$ and $x_{2}$ is the second period consumption. Hence a contract $(s, R)$ uniquely corresponds to a net endowment $\mathbf{x}=\left(x_{1}, x_{2}\right)$. Recast in terms of the net endowment, the actuarial fairness condition (8) for type $i$ reads as follows: $\mathbf{x}^{i}$ is actuarially fair for type $i$ if and only if

$$
x_{1}^{i}+\pi\left(h^{i}\right) x_{2}^{i}=\omega, i=L, H
$$

Since there is a one-to-one correspondence between contracts $(s, R)$ and net endowments $\mathbf{x}$ we will refer to both interchangeably as contracts.

For most of the analysis it will be assumed that the health investment $h$ is unobservable, therefore it is useful to work out this case.

When the investment in health care $h$ is not observable individuals can take hidden actions to affect their longevity (in annuity market there is moral hazard): individuals choose the optimal level of $h$ in response to contract $\mathbf{x}$ offered by annuity supplying firms (see, e.g., Davies and Kuhn (1992)).

Given $\mathbf{x}$ the optimal choice with respect to the health investment $h^{i}$ taken by individual type $i$ generates an indirect utility

$$
V^{i}(\mathbf{x}) \equiv \max _{h^{i}} u\left(x_{1}-c\left(h^{i}\right)\right)+\beta^{i} \pi\left(h^{i}\right) u\left(x_{2}\right), i=L, H
$$

Note that the objective function is strictly concave; hence the first order condition

$$
\frac{u^{\prime}\left(x_{1}-c\left(h^{i}\right)\right)}{\beta^{i}}=\frac{\pi^{\prime}}{c^{\prime}} u\left(x_{2}\right), i=L, H
$$

is both necessary and sufficient for an optimum. Let the associated optimal investment be denoted by $h^{i}(\mathbf{x})$, where the superscript $i$ indicates that the two types $L$ and $H$ do not choose the same level of investment given $\mathbf{x}$. Indeed, it is easy to see from equation (12) that

$$
\frac{u^{\prime}\left(x_{1}-c\left(h^{L}(\mathbf{x})\right)\right)}{\beta^{L}}=\frac{u^{\prime}\left(x_{1}-c\left(h^{H}(\mathbf{x})\right)\right)}{\beta^{H}}
$$

Since $\beta^{L}<\beta^{H}$ implies that

$$
u^{\prime}\left(x_{1}-c\left(h^{L}(\mathbf{x})\right)\right)<u^{\prime}\left(x_{1}-c\left(h^{H}(\mathbf{x})\right)\right)
$$

for all $\mathbf{x}$ we have

$$
h^{L}(\mathbf{x})<h^{H}(\mathbf{x})
$$

It is useful to characterize the partial derivatives of the individual's indirect utility; from the envelope theorem we obtain

$$
\begin{aligned}
& V_{1}^{i}=u^{\prime}\left(x_{1}-c\left(h^{i}(\mathbf{x})\right)\right)>0, i=L, H \\
& V_{2}^{i}=\beta^{i} \pi\left(h^{i}(\mathbf{x})\right) u^{\prime}\left(x_{2}\right)>0, i=L, H
\end{aligned}
$$


From equation (14) we know that $V_{1}^{L}<V_{1}^{H}$. Since $\beta^{L}<\beta^{H}$ implies $h^{L}(\mathbf{x})<$ $h^{H}(\mathbf{x})$ it follows that $V_{2}^{L}<V_{2}^{H}$. Consider then the marginal rate of substitution between $x_{1}$ and $x_{2}$

$$
\frac{V_{1}^{i}}{V_{2}^{i}}=\frac{u^{\prime}\left(x_{1}-c\left(h^{i}(\mathbf{x})\right)\right)}{\beta^{i} \pi\left(h^{i}(\mathbf{x})\right) u^{\prime}\left(x_{2}\right)}=\frac{\pi^{\prime}}{c^{\prime}} \frac{1}{\pi\left(h^{i}(\mathbf{x})\right)} \frac{u\left(x_{2}\right)}{u^{\prime}\left(x_{2}\right)}, i=L, H
$$

where $\pi^{\prime}$ and $c^{\prime}$ are constants; since $h^{L}(\mathbf{x})<h^{H}(\mathbf{x})$ we can say that the indifference curve of $L$ over $\left(x_{1}, x_{2}\right)$ is flatter than that one of $H$ : the individual preferences are single crossing.

From equation (12) we can also establish the following derivatives

$$
\begin{aligned}
& h_{1}^{i}=\frac{1}{c^{\prime}}>0, i=L, H \\
& h_{2}^{i}=-\beta^{i} \frac{\pi^{\prime}}{\left(c^{\prime}\right)^{2}} \frac{u^{\prime}\left(x_{2}\right)}{u^{\prime \prime}\left(x_{1}-c\left(h^{i}(\mathbf{x})\right)\right)}>0, i=L, H
\end{aligned}
$$

and then the level of investment in health care $h$ is positively affected both by $x_{1}$ (more net resources are available in the first period, more the individuals are inclined to invest in health care $h$ ) and by $x_{2}$ (more net resources are available in the second period, more the individuals desire to increase their survival probability $\pi(h))$.

\section{Competitive Equilibrium with Public Information}

In this section both the rate of time preference $\beta^{i}$ and the investment in health care $h^{i}$ of any agent $i$ are assumed to be public information.

The public information environment is characterized by the absence of crosssubsidization across different types and by the fact that the investment in health care $h$ is contractible. Then we can analyse the public information setting as if individuals of different groups were completely separated into different markets.

The competition among firms implies that they offer contracts that maximize the ex ante utility of each type $i$ subject to the actuarial fairness condition (8). Then firms decide the values of premium $s$ and rate of return $R$ of separating contracts by maximizing the expected utility of the representative agent of group $i=L, H$

$$
\begin{array}{ll}
\max _{s^{i}, h^{i}} & u\left(\omega-c\left(h^{i}\right)-s^{i}\right)+\beta^{i} \pi\left(h^{i}\right) u\left(s^{i} R\left(h^{i}\right)\right) \\
\text { s.t. } & R\left(h^{i}\right)=\frac{1}{\pi\left(h^{i}\right)}\left(\lambda^{i}\right)
\end{array}, i=L, H
$$

Since firms offer the actuarially fair rates of return, we obtain the Euler equation with $r=0$ (the consumption path reflects the individual's idiosyncratic 
time-preference)

$$
\frac{u^{\prime}\left(c_{1}^{i}\right)}{u^{\prime}\left(c_{2}^{i}\right)}=\beta^{i}, i=L, H
$$

and the investment rule

$$
\left.\begin{array}{rl}
\left(1+\frac{\pi^{\prime}}{c^{\prime}} c_{2}^{i}\right) \frac{u^{\prime}\left(c_{1}^{i}\right)}{\beta^{i}} & =\frac{\pi^{\prime}}{c^{\prime}} u\left(c_{2}^{i}\right) \\
\text { or }\left(1+\frac{\pi^{\prime}}{c^{\prime}} c_{2}^{i}\right)
\end{array}\right), i=L, H
$$

The second version of equation (23) does not contain any type specific terms: we can conclude that $c_{2}$ is individual type independent and we can argue that members of both groups choose the same level of consumption in the second period $c_{2}^{L}=c_{2}^{H}=c_{2}>0$. From equation (22) since $\beta^{L}<\beta^{H}$ we can argue that $c_{1}^{L}>c_{1}^{H}$. Since $c_{2}^{L}=c_{2}^{H}$ it follows that

$$
s^{L} R\left(h^{L}\right)=s^{H} R\left(h^{H}\right)
$$

and then $s^{i} R\left(h^{i}\right)$ with $i=L, H$ is constant across types. Hence it must be either $\left(s^{L}, h^{L}\right) \gg\left(s^{H}, h^{H}\right)$ or $\left(s^{L}, h^{L}\right) \ll\left(s^{H}, h^{H}\right)$. But since $c_{1}^{i}=\omega-$ $c\left(h^{i}\right)-s^{i}$ for $i=L, H$, from the fact that $c_{1}^{L}>c_{1}^{H}$ it follows that

$$
\left(s^{L}, h^{L}\right) \ll\left(s^{H}, h^{H}\right)
$$

Finally $h^{L}<h^{H}$ implies $\pi\left(h^{L}\right)<\pi\left(h^{H}\right)$ and hence individuals with a larger rate of time preference have a higher survival probability. Then, by actuarial fairness (8), contracts offered by firms are characterized by

$$
R\left(h^{L}\right)>R\left(h^{H}\right)
$$

In this setting agents with different survival probability purchase annuities with different rate of return and each group obtains an actuarially fair contract. Hence in a competitive equilibrium agents equate their expected intertemporal marginal rate of substitution to the rate of return on saving that they face

$$
\frac{1}{\pi\left(h^{i}\right)} \frac{u^{\prime}\left(c_{1}^{i}\right)}{\beta^{i} u^{\prime}\left(c_{2}^{i}\right)}=R^{i}, i=L, H
$$

Consequently, as usual, with full information the competitive equilibrium is (ex ante) Pareto optimal.

\section{Private Information}

In this section we consider the case of private information regarding the investments in health care $h$ or/and the rates of time preference $\beta$. 


\subsection{A Pure Moral Hazard Equilibrium}

We start the analysis of private information by considering a situation in which the individual types are still observable, but the investments in health care $h$ made by the individuals belonging to both groups are not observable.

Since individual types are observable, also in this case there can be no crosssubsidization across different types; then the zero profits condition (8) holds for each group, i.e. the annuity supplying firms offer separating contracts. However, the investment in health care is not observable and then individuals can take hidden actions to affect their longevity (in annuity market there is moral hazard). In fact each individual $i=L, H$ chooses the optimal level of $\tilde{h}^{i}$ in response to contract $\tilde{\mathbf{x}}^{i}$ offered by annuity supplying firms: for the individual $i$ the contract $\tilde{\mathbf{x}}^{i}$ is given (see, e.g., Davies and Kuhn (1992)).

Definition 1 A set of contracts is a pure moral hazard equilibrium (a separating equilibrium) if no firm can increase its profit by adjusting its menu of contracts given the menus of contracts offered by the other firms and given that individuals choose rationally among contracts given their equilibrium investment in health care, i.e. the individuals choose the contract that yield highest expected utility given their equilibrium investment in health care.

It thus follows that the separating contract $\tilde{\mathbf{x}}^{i}$ obtained by each type $i=$ $L, H$ will be actuarially fair given his equilibrium investment in health care (see maximization problem (11)). Hence the competitive equilibrium solves

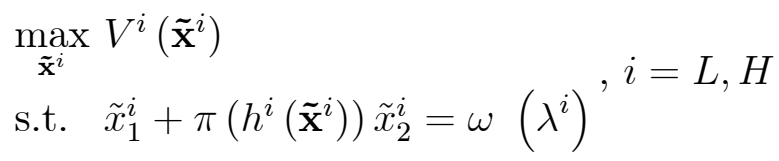

After formulating the $\mathcal{L}$ agrangian, by using the equations (16) and (17) to replace $V_{1}^{i}$ and $V_{2}^{i}$ and the short-hands $\tilde{h}^{i}=h^{i}\left(\tilde{\mathbf{x}}^{i}\right), \tilde{c}^{i}=c\left(h^{i}\left(\tilde{\mathbf{x}}^{i}\right)\right)$ and $\tilde{\pi}^{i}=$ $\pi\left(h^{i}\left(\tilde{\mathbf{x}}^{i}\right)\right)$ we can combine the FOCs to obtain the Euler equation that applies in case of moral hazard equilibrium

$$
\frac{u^{\prime}\left(\tilde{x}_{1}^{i}-\tilde{c}^{i}\right)}{u^{\prime}\left(\tilde{x}_{2}^{i}\right)}=\beta^{i} \tilde{\pi}^{i} \frac{\left(1+\pi^{\prime} h_{1}^{i} \tilde{x}_{2}^{i}\right)}{\left(\tilde{\pi}^{i}+\pi^{\prime} h_{2}^{i} \tilde{x}_{2}^{i}\right)}, i=L, H
$$

where $h_{1}^{i}$ and $h_{2}^{i}$ are defined in (19) and (20). Note that if the investment $\tilde{h}^{i}$ had been unaffected by the contract, then the consumption path would have been determined solely by the individual's time preferences described by equation (22).

The Euler equation (29) can be further manipulated through equations (19), 
(1) and (2) to read

$$
\frac{u^{\prime}\left(\tilde{x}_{1}^{i}-\tilde{c}^{i}\right)}{u^{\prime}\left(\tilde{x}_{2}^{i}\right)}=\beta^{i} \frac{\left(1+\frac{\pi^{\prime}}{c^{\prime}} \tilde{x}_{2}^{i}\right)}{\left(1+\frac{h_{2}^{i}}{\tilde{h}^{i}} \tilde{x}_{2}^{i}\right)}, i=L, H
$$

In case of pure moral hazard, the equilibrium contracts leave the Euler equation distorted relative to the first-best case in equation (22): the slope is adjusted so as to provide the right incentives to invest.

To analyse the direction of this adjustment it is useful to follow Davies and Kuhn (1992) and then to apply the first-order condition approach (see, e.g., Mas-Colell, Whinston and Green (1995)).

Because individuals can take hidden actions to affect their longevity, competitive firms offer the utility-maximizing actuarially fair annuity contracts $\tilde{\mathbf{x}}^{i}$ given that individuals choose the optimal level of $\tilde{h}^{i}$ in response to these contracts (see maximization problem (11)) - incentive constraints (see, e.g., Davies and Kuhn (1992)). Hence the competitive equilibrium solves

$$
\begin{array}{ll}
\max _{\tilde{\mathbf{x}}^{i}, \tilde{h}^{i}} & u\left(\tilde{x}_{1}^{i}-c\left(\tilde{h}^{i}\right)\right)+\beta^{i} \pi\left(\tilde{h}^{i}\right) u\left(\tilde{x}_{2}^{i}\right) \\
\text { s.t. } & \tilde{x}_{1}^{i}+\pi\left(\tilde{h}^{i}\right) \tilde{x}_{2}^{i}=\omega\left(\lambda^{i}\right) \quad, i=L, H \\
& \tilde{h}^{i} \text { solves } \max _{h^{i}} u\left(\tilde{x}_{1}^{i}-c\left(h^{i}\right)\right)+\beta^{i} \pi\left(h^{i}\right) u\left(\tilde{x}_{2}^{i}\right) \quad\left(\mu^{i}\right)
\end{array}
$$

Since we have a continuous set of possible actions $\tilde{h}^{i} \in\left[0, h^{\max }\right]$ we have an infinity of incentive constraints. One trick used in this case is to replace the incentive constraint with the FOC (12) - first-order condition approach (see, e.g., Mas-Colell, Whinston and Green (1995)): $\tilde{h}^{i}$, with $i=L, H$, must be incentive compatible in the sense that it must satisfy the consumer's investment incentives as described by the FOC (12)

$$
\begin{array}{ll}
\max _{\tilde{\mathbf{x}}^{i}, \tilde{h}^{i}} & u\left(\tilde{x}_{1}^{i}-c\left(\tilde{h}^{i}\right)\right)+\beta^{i} \pi\left(\tilde{h}^{i}\right) u\left(\tilde{x}_{2}^{i}\right) \\
\text { s.t. } & \tilde{x}_{1}^{i}+\pi\left(\tilde{h}^{i}\right) \tilde{x}_{2}^{i}=\omega\left(\lambda^{i}\right) \quad, i=L, H \\
& \frac{u^{\prime}\left(\tilde{x}_{1}^{i}-c\left(\tilde{h}^{i}\right)\right)}{\beta^{i}}=\frac{\pi^{\prime}}{c^{\prime}} u\left(\tilde{x}_{2}^{i}\right) \quad\left(\mu^{i}\right)
\end{array}
$$

and the constraint binds $\left(\mu^{i}>0\right)$ if $\tilde{h}^{i}>h^{i}$, i.e. if the level of the investment in health care chosen in case of private information is larger then the level chosen in case of public information.

If we formulate the $\mathcal{L}$ agrangian according to this approach, by using the short-hands $\tilde{c}^{i}=c\left(\tilde{h}^{i}\right)$ and $\tilde{\pi}^{i}=\pi\left(\tilde{h}^{i}\right)$ in the combination of the FOCs, we obtain the following expression for the Euler equation distorted relative to the 
first-best case in equation (22)

$$
\frac{u^{\prime}\left(\tilde{x}_{1}^{i}-\tilde{c}^{i}\right)}{u^{\prime}\left(\tilde{x}_{2}^{i}\right)}=\beta^{i}\left(1+\mu^{i} \frac{1}{\tilde{h}^{i}}\right)\left(1+\frac{\pi^{\prime}}{c^{\prime}} \tilde{x}_{2}^{i}\right), i=L, H
$$

By applying the equations (19) and (20), if we compare the equation (33) with the equation (30) we can say that the multiplier on the incentive constraint is negative

$$
\mu^{i}=-\frac{h_{2}^{i} \tilde{x}_{2}^{i}}{1+\frac{h_{2}^{i}}{\tilde{h}^{i}} \tilde{x}_{2}^{i}}<0, i=L, H
$$

where $h_{2}^{i}$ is defined in (20). If we overlook the FOC (12), we obtain also a temporary expression for the investment rule distorted relative to the first version of equation (23)

$$
\left(1+\frac{\pi^{\prime}}{c^{\prime}} \tilde{x}_{2}^{i}\right) \frac{u^{\prime}\left(\tilde{x}_{1}^{i}-\tilde{c}^{i}\right)}{\beta^{i}}=\frac{\pi^{\prime}}{c^{\prime}} u\left(\tilde{x}_{2}^{i}\right)+\mu^{i}\left(c^{\prime}+\pi^{\prime} \tilde{x}_{2}^{i}\right) \frac{u^{\prime \prime}\left(\tilde{x}_{1}^{i}-\tilde{c}^{i}\right)}{\beta^{i}}, i=L, H
$$

Since the last fraction of the equation (35) is strictly positive

$$
\mu^{i}\left(c^{\prime}+\pi^{\prime} \tilde{x}_{2}^{i}\right) \frac{u^{\prime \prime}\left(\tilde{x}_{1}^{i}-\tilde{c}^{i}\right)}{\beta^{i}}>0, i=L, H
$$

we can conclude that the investment in health care $\tilde{h}^{i}$, with $i=L, H$, is distorted upwards. Since the risk of long-life is insured and covered by the annuity supplying firms and since the investments in health care $h$ are not observable, the individuals tend to overinvest in health care. In order to reduce the investment incentives the contracts offered are characterized by lower rates of return and higher premiums.

In table 1 we can see that when $\beta^{L}=0.3$ and $\beta^{H}=1.0$ we have $\tilde{h}^{L}(236.29)>$ $h^{L}(160.55), \tilde{R}^{L}(3.39)<R^{L}(4.98), \tilde{s}^{L}(46.92)>s^{L}(45.39)$ and $\tilde{h}^{H}(535.80)>$ $h^{H}(504.87), \tilde{R}^{H}(1.49)<R^{H}(1.58), \tilde{s}^{H}(144.06)>s^{H}(142.74)$ and when $\beta^{L}=$ 0.6 and $\beta^{H}=0.7$ we have $\tilde{h}^{L}(455.99)>h^{L}(406.49), \tilde{R}^{L}(1.75)<R^{L}(1.97)$, $\tilde{s}^{L}(116.96)>s^{L}(114.92)$ and $\tilde{h}^{H}(126.66)>h^{H}(124.86), \tilde{R}^{H}(1.65)<R^{H}(1.81)$, $\tilde{s}^{H}(126.66)>s^{H}(124.86)$.

However, given the FOC (12) the distorted investment rule becomes

$$
\begin{aligned}
& \frac{\pi^{\prime}}{c^{\prime}} \tilde{x}_{2}^{i} u^{\prime}\left(\tilde{x}_{1}^{i}-\tilde{c}^{i}\right)=\mu^{i}\left(c^{\prime}+\pi^{\prime} \tilde{x}_{2}^{i}\right) u^{\prime \prime}\left(\tilde{x}_{1}^{i}-\tilde{c}^{i}\right) \\
& \text { or } \frac{\pi^{\prime}}{c^{\prime}} \tilde{x}_{2}^{i} u^{\prime}\left(\tilde{x}_{2}^{i}\right)=\mu^{i} \frac{c^{\prime}}{\left(1+\mu^{i} \frac{1}{\tilde{h}^{i}}\right)} \frac{u^{\prime \prime}\left(\tilde{x}_{1}^{i}-\tilde{c}^{i}\right)}{\beta^{i}} \quad, i=L, H
\end{aligned}
$$

Hence each individual type is worse off under moral hazard than in the equilibrium with full information: when there is moral hazard in the annuity market all individuals are affected by an inefficiency

$$
V^{i}\left(\tilde{\mathbf{x}}^{i}\right)<V^{i}\left(\mathbf{x}^{i}\right), i=L, H
$$


Let $\tilde{\mathbf{x}}^{L}$ and $\tilde{\mathbf{x}}^{H}$ be the equilibrium contracts under pure moral hazard; generally we have that if a type $H$ agent purchased the contract designed for members of group $L$ he would obtain a larger utility, i.e. $\hat{V}^{H}\left(\tilde{\mathbf{x}}^{L}\right)>V^{H}\left(\tilde{\mathbf{x}}^{H}\right)$. Hence, the equilibrium strictly relies on the observability of individual types - members of group $H$ would, if possible, choose the contract intended for members of group $L$.

\subsection{A Pure Adverse Selection Equilibrium}

Suppose that not only the investments in health care $h$, but also the heterogeneous rates of time preference $\beta$ are not observable. Moreover let us assume that the investments in health care $h$ are not modifiable with respect to the values obtained in competitive equilibrium with public information and determined by the investment rule (23): the investment in health care $h$ is not a choice variable and then the moral hazard problem doesn't occur. Since individuals cannot take hidden actions to affect their longevity (the equilibrium will be without the moral hazard aspects) and since the annuity supplying firms cannot identify the individual types from the unobservable investments in health care ${ }^{7}$, in this case there is a pure adverse selection problem ${ }^{8}$.

It is interesting to compare the solution from this scenario with the pure moral hazard case - outlined above - where the individual types are still observable and the investments in health care $h$ are not observable (and modifiable).

We focus here on a separating equilibrium: in that case there can be no cross-subsidization among different contracts. Hence each individual type $i$ must obtain a contract that is actuarially fair given the investment in health care $h^{i}$. In the separating equilibrium the contracts that are offered will try to maximize the utility of each type, but have to do so under the constraint that type $H$ individual does not prefer the contract offered to type $L$ individual (incentive-compatibility or self-selection constraint).

In fact, in case of separating contracts with private information firms offer to type $H$ agents the same contract $\mathbf{x}^{H}$ they would offer in case of complete competitive equilibrium with public information (see maximization problem

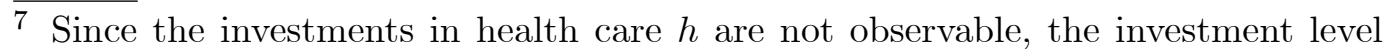
cannot be a "signal" for annuity supplying firms.

8 Suppose that the investments in health care $h$ are observable while the heterogeneous rates of time preference $\beta$ are unobservable. Since individuals cannot take hidden actions to affect their longevity, also in this case the equilibrium will be without the moral hazard aspects. However if type $H$ agents purchased the contract designed for type $L$ agents, since the investments in health care $h$ are observable they should invest in heath care the same amount invested by type $L$ agents; consequently their survival probability would be not $\pi\left(h^{H}\right)$ but $\pi\left(\grave{h}^{L}\right)$. On the contrary in the adverse selection scenario analysed by Rothschild and Stiglitz (1976), Wilson (1977) and Eckstein, Eichenbaum and Peled (1985) mimicking type $H$ agents mantain their exogeneous survival probability $\pi^{H}$. 
(21)). However, since contract $\grave{\mathbf{x}}^{L}$ is actuarially fair for members of group $L$ only, if members of group $H$ purchased it profits of firms would necessarily be negative.

Definition 2 Wilson (1977): A set of contracts is a Wilson equilibrium (a pure adverse selection equilibrium) if no firm has a profitable deviation that remains profitable once existing contracts offered by other firms that lose money after the deviation are withdrawn (see, e.g. Mas-Colell, Whinston and Green (1995)).

Thus competitive firms offer to members of group $L$ the utility-maximizing actuarially fair annuity contract $\grave{\mathbf{x}}^{L}$ subject to the constraint that contract of separating equilibrium for group $L$ must not be more attractive to members of group $H$ than contract $\mathbf{x}^{H}$ - incentive-compatibility or self-selection constraint (see, e.g., Eckstein, Eichenbaum and Peled (1985)).

Since the investment in health care $h$ is not a choice variable - $h$ is unobservable but not modifiable and thus still determined by the undistorted investment rule (23) - it is convenient to work with the original formulation of the individuals' preferences. Hence the equilibrium can be described as

$$
\begin{array}{ll}
\max _{\grave{\mathbf{x}}^{L}, \mathbf{x}^{H}} & u\left(\grave{x}_{1}^{L}-c\left(h^{L}\right)\right)+\beta^{L} \pi\left(h^{L}\right) u\left(\grave{x}_{2}^{L}\right) \\
\text { s.t. } & \grave{x}_{1}^{L}+\pi\left(h^{L}\right) \grave{x}_{2}^{L}=\omega\left(\lambda^{L}\right) \\
& x_{1}^{H}+\pi\left(h^{H}\right) x_{2}^{H}=\omega\left(\lambda^{H}\right) \\
& u\left(x_{1}^{H}-c\left(h^{H}\right)\right)+\beta^{H} \pi\left(h^{H}\right) u\left(x_{2}^{H}\right) \\
& \geq u\left(\grave{x}_{1}^{L}-c\left(h^{H}\right)\right)+\beta^{H} \pi\left(h^{H}\right) u\left(\grave{x}_{2}^{L}\right)
\end{array}
$$

and the constraint binds $(\sigma>0)$ if $\hat{V}^{H}\left(\mathbf{x}^{L}\right)>V^{H}\left(\mathbf{x}^{H}\right)$, i.e. if members of group $H$ prefer the contract $\mathbf{x}^{L}$ (the contract offered to members of group $L$ in case of public information) to contract $\mathbf{x}^{H}$ (the contract offered to them in case of public information).

After formulating the $\mathcal{L}$ agrangian, we combine the FOCs by using the shorthands $c^{L}=c\left(h^{L}\right)$ and $c^{H}=c\left(h^{H}\right)$. Hence we see that for type $H$ individual the undistorted Euler equation (22) applies

$$
\frac{u^{\prime}\left(x_{1}^{H}-c^{H}\right)}{u^{\prime}\left(x_{2}^{H}\right)}=\beta^{H}
$$

For type $L$ individual, on the other hand, we obtain the following expression for the ratio of the marginal utilities

$$
\frac{u^{\prime}\left(\grave{x}_{1}^{L}-c\left(h^{L}\right)\right)}{u^{\prime}\left(\grave{x}_{2}^{L}\right)}=\beta^{L} \frac{\left(1-\sigma \frac{\beta^{H}}{\beta^{L}} \frac{\pi\left(h^{H}\right)}{\pi\left(h^{L}\right)}\right)}{(1-\sigma)}
$$


Hence, if the self-selection constraint were not binding (when $\hat{V}^{H}\left(\grave{\mathbf{x}}^{L}\right) \leq$ $V^{H}\left(\mathbf{x}^{H}\right)$ we have $\sigma=0$ ), the Euler equation would be undistorted (see equation (22)). However, when $\sigma>0$ with $\frac{\beta^{H}}{\beta^{L}} \frac{\pi\left(h^{H}\right)}{\pi\left(h^{L}\right)}>1$ we see that the last fraction of equation (40) is less than unity

$$
\frac{\left(1-\sigma \frac{\beta^{H}}{\beta^{L}} \frac{\left(h^{H}\right)}{\pi\left(h^{L}\right)}\right)}{(1-\sigma)}<1
$$

The steepness of type L's consumption path is strictly distorted. In particular, it implies that the path is front-loaded in the sense that the first period consumption is high and the second period consumption is low relative to the undistorted path. In fact type $H$ individual is tempted to mimic type $L$ individual and has a particular taste for second period consumption. By making type $L$ 's consumption path front-loaded the self-selection constraint can be relaxed.

In table 1 we can see that when $\beta^{L}=0.3$ and $\beta^{H}=1.0$ we have $\grave{s}^{L}(23.16)<$ $s^{L}(45.39)$ and then $\grave{x}_{1}^{L}(976.83)>x_{1}^{L}(954.61)$ and $\grave{x}_{2}^{L}(115.45)<x_{2}^{L}(226.18)$ and when $\beta^{L}=0.6$ and $\beta^{H}=0.7$ we have $\grave{s}^{L}(85.13)<s^{L}(114.92)$ and then $\grave{x}_{1}^{L}(914.87)>x_{1}^{L}(885.08)$ and $\grave{x}_{2}^{L}(167.54)<x_{2}^{L}(226.18)$.

\subsection{Adverse Selection with Endogenous Heterogeneity}

So far we have shown the following.

(1) If the individual types were observable but the investments in health care were not (pure moral hazard case), then both individual types would face distorted Euler equations (see equations (30) and (33)) and their health investments would be above the first-best level (see the distorted investment rule (37)).

(2) If both the investments in health care and the individual types were unobservable but the investments were not modifiable (pure adverse selection case) then type $L$ individuals would face an undistorted investment rule (see equations (23)) but a distorted Euler equation (see equation (40)): it would be asked them to pay a premium that is low relative to the first-best. Type $H$ individuals, on the other hand, would be undistorted in both dimensions (see the Euler equation (39) and the investment rule (23)).

We can continue the analysis by considering a situation in which not only the investments in health care $h$ (choice variable), but also the individual types $\beta$ are not observable.

Definition 3 In case of adverse selection with endogenous heterogeneity a set of contracts is an equilibrium if no firm can increase its profit by adjusting its menu of contracts given the menus of contracts offered by the other firms, 
i.e. no firm has a profitable deviation that remains profitable once existing contracts offered by other firms that lose money after the deviation are withdrawn, and given that individuals choose rationally among contracts given their equilibrium investment in health care, i.e. the individuals choose the contract that yield highest expected utility given their equilibrium investment in health care.

\section{Separating Contracts}

We consider first the case of a separating equilibrium. In the separating equilibrium there can be no cross-subsidization among different contracts: each individual type must obtain an actuarially fair contract (at his equilibrium investment in health care), and, moreover, it must be the case that no individual type prefers the contract provided to the other type.

The contract $\tilde{\mathbf{x}}^{L}$, the contract offered to members of group $L$, and the contract $\tilde{\mathbf{x}}^{H}$, the contract offered to members of group $H$, are characterized by $\hat{V}^{H}\left(\tilde{\mathbf{x}}^{L}\right)>V^{H}\left(\tilde{\mathbf{x}}^{H}\right)$ and then members of group $H$ prefer contract $\tilde{\mathbf{x}}^{L}$ to contract $\tilde{\mathbf{x}}^{H}$.

Since members of group $H$ have hidden information about their longevity, if a firm offered the contract $\tilde{\mathbf{x}}^{L}$ individuals of group $H$ would purchase this contract instead of the contract $\tilde{\mathbf{x}}^{H}$. However, contract $\tilde{\mathbf{x}}^{L}$ is actuarially fair for members of group $L$ only: if members of group $H$ purchased it profits of firms would necessarily be negative.

Thus competitive firms offer to members of group $L$ the utility-maximizing actuarially fair separating annuity contract $\check{\mathbf{x}}^{L}$ (i) given that type $L$ and type $H$ individuals choose the optimal level of $h$ in response to contracts offered to them (see maximization problem (11)) - implicit incentive constraint (see, e.g., Davies and Kuhn (1992)) and (ii) subject to the constraint that the separating contract designed for group $L$ must not be more attractive to members of group $H$ than contract $\tilde{\mathbf{x}}^{H}$ - incentive-compatibility or self-selection constraint (see, e.g., Eckstein, Eichenbaum and Peled (1985)).

Then the maximization problem in case of separating contracts with private information is

$$
\begin{array}{ll}
\max _{\check{\mathbf{x}}^{L}, \tilde{\mathbf{x}}^{H}} & V^{L}\left(\check{\mathbf{x}}^{L}\right) \\
\text { s.t. } & \check{x}_{1}^{L}+\pi\left(h^{L}\left(\check{\mathbf{x}}^{L}\right)\right) \check{x}_{2}^{L}=\omega\left(\lambda^{L}\right) \\
& \tilde{x}_{1}^{H}+\pi\left(h^{H}\left(\tilde{\mathbf{x}}^{H}\right)\right) \tilde{x}_{2}^{H}=\omega\left(\lambda^{H}\right) \\
& V^{H}\left(\tilde{\mathbf{x}}^{H}\right) \geq \hat{V}^{H}\left(\check{\mathbf{x}}^{L}\right) \quad(\sigma)
\end{array}
$$

Note how this problem is distinct from that studied by Eckstein, Eichenbaum and Peled (1985); in their framework each individual type is associated with a fixed but type-specific survival probability $\pi$. In this framework the heterogeneity in the survival probability is endogenous and depends on the contract itself. Specifically the heterogeneity lies in the underlying preferences which cause the two different types to choose different levels of investments in health care $h$ and hence different survival probabilities $\pi(h)$ at any give 
contract $\mathbf{x}$.

We formulate the $\mathcal{L}$ agrangian by focusing on the case where the self-selection constraint is binding and then we combine the FOCs by using the equations (16) and (17) to replace $V_{1}^{i}$ and $V_{2}^{i}$ and the short-hands $h^{i}=h^{i}\left(\mathbf{x}^{i}\right), c^{i}=$ $c\left(h^{i}\left(\mathbf{x}^{i}\right)\right)$ and $\pi^{i}=\pi\left(h^{i}\left(\mathbf{x}^{i}\right)\right)$. Hence we see that for type $H$ individual the distorted Euler equation (30) obtained in the pure moral hazard case applies

$$
\frac{u^{\prime}\left(\tilde{x}_{1}^{H}-\tilde{c}^{H}\right)}{u^{\prime}\left(\tilde{x}_{2}^{H}\right)}=\beta^{H} \frac{\left(1+\frac{\pi^{\prime}}{c^{\prime}} \tilde{x}_{2}^{H}\right)}{\left(1+\frac{h_{2}^{H}}{\tilde{h}^{H}} \tilde{x}_{2}^{H}\right)}
$$

and for type $L$ individual, on the other hand, we obtain the following expression

$$
\frac{u^{\prime}\left(\check{x}_{1}^{L}-\check{c}^{L}\right)-\sigma u^{\prime}\left(\check{x}_{1}^{L}-\hat{c}^{H}\right)}{\left(1-\sigma \frac{\beta^{H}}{\beta^{L}} \frac{\hat{\pi}^{H}}{\check{\pi}^{L}}\right) u^{\prime}\left(\check{x}_{2}^{L}\right)}=\beta^{L} \frac{\left(1+\frac{\pi^{\prime}}{c^{\prime}} \check{x}_{2}^{L}\right)}{\left(1+\frac{h_{2}^{L}}{\check{h}^{L}} \check{x}_{2}^{L}\right)}
$$

where $h_{2}^{L}$ and $h_{2}^{H}$ are defined in (20).

If the self-selection constraint were not binding (when $\hat{V}^{H}\left(\check{\mathbf{x}}^{L}\right) \leq V^{H}(\tilde{\mathbf{x}})$ we have $\sigma=0$ ), the Euler equation would be the distorted Euler equation (30) obtained in the pure moral hazard case. However, when $\sigma>0$ with $\frac{\beta^{H}}{\beta^{L}} \frac{\hat{\pi}^{H}}{\check{\pi}^{L}}>1$ the steepness of type L's consumption path is affected by an additional distortion. Specifically we can deduce that (i) type $L$ 's investment in health care is distorted upwards relative to the undistorted investment rule (23) - since the individuals tend to overinvest in health care, in order to reduce the investment incentives the contract offered is characterized by lower rate of return - and (ii) type L's consumption path is front-loaded in the sense that the first period consumption is high and the second period consumption is low relative to the undistorted path - since type $H$ individuals have a particular taste for second period consumption, by making type $L$ 's consumption path front-loaded the self-selection constraint can be relaxed.

Hence when there is adverse selection in the annuity market individuals of group $L$ are affected by a negative externality

$$
V^{L}\left(\check{\mathbf{x}}^{L}\right)<V^{L}\left(\tilde{\mathbf{x}}^{L}\right)<V^{L}\left(\mathbf{x}^{L}\right)
$$

The results of simulation are summarized in table 1 : when $\beta^{L}=0.3$ and $\beta^{H}=1.0$ we have not only $\check{h}^{L}(193.15)>h^{L}(160.55)$ but also $\check{s}^{L}(22.34)<$ $s^{L}(45.39)$ (while $\check{s}^{L}(22.34)<\grave{s}^{L}(23.16)$, we have $\check{h}^{L}(193.15)<\tilde{h}^{L}(236.29)$ ), $\check{x}_{1}^{L}(977.66)>x_{1}^{L}(954.61), \check{x}_{2}^{L}(92.54)<x_{2}^{L}(226.18)$ and then $V^{L}\left(\check{\mathbf{x}}^{L}\right)(6.9295)<$ $V^{L}\left(\tilde{\mathbf{x}}^{L}\right)(6.9378)<V^{L}\left(\mathbf{x}^{L}\right)(6.9517)$ and when $\beta^{L}=0.6$ and $\beta^{H}=0.7$ we have not only $\check{h}^{L}(464.28)>h^{L}(406.49)$ but also $\check{s}^{L}(86.94)<s^{L}(114.92)$ 
(while $\check{s}^{L}(86.94)>\grave{s}^{L}(85.13)$, we have $\left.\check{h}^{L}(464.28)>\tilde{h}^{L}(455.99)\right), \check{x}_{1}^{L}(913.06)>$ $x_{1}^{L}(885.08), \check{x}_{2}^{L}(149.80)<x_{2}^{L}(226.18)$ and then $V^{L}\left(\check{\mathbf{x}}^{L}\right)(7.5516)<V^{L}\left(\tilde{\mathbf{x}}^{L}\right)(7.5671)<$ $V^{L}\left(\mathbf{x}^{L}\right)(7.5849)$.

Table 1. Separating Contracts

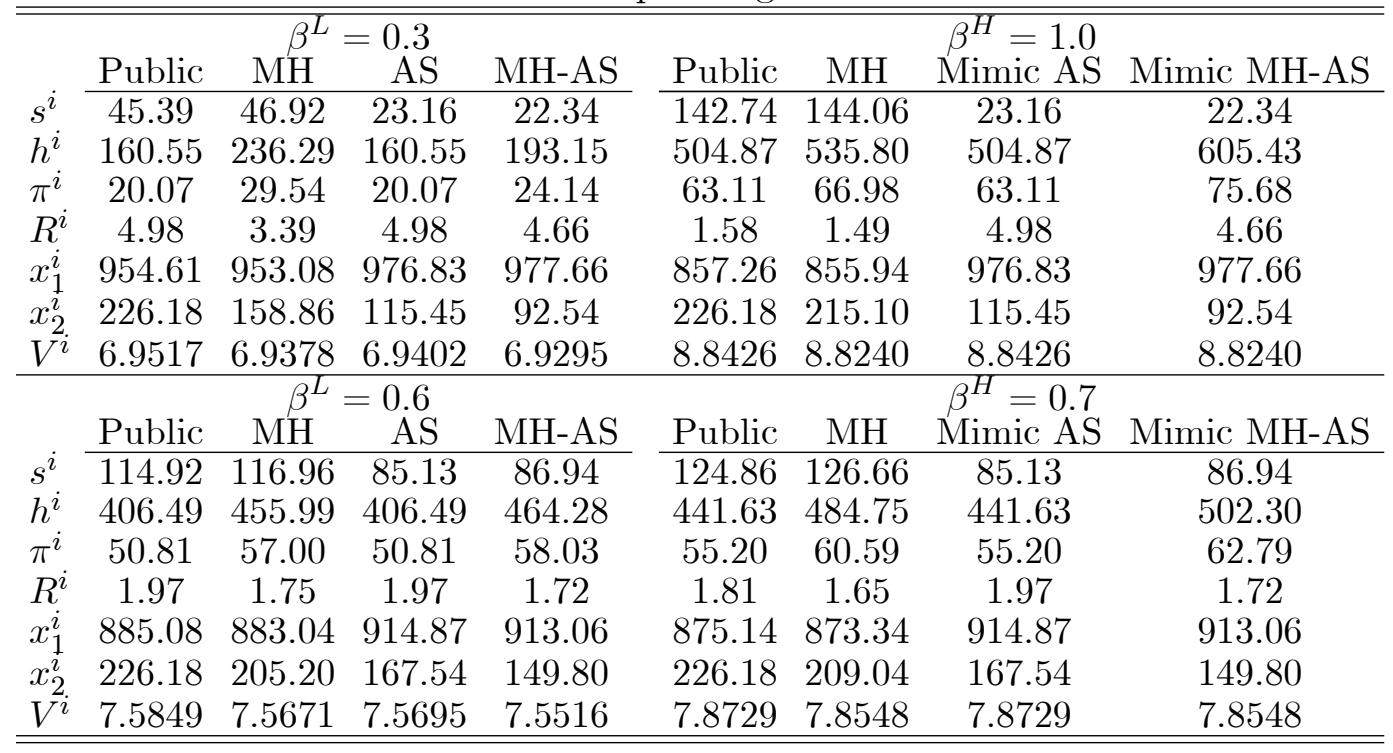

In case of pure moral hazard equilibrium both type $L$ individuals and type $H$ individuals are worse off than they would be in case of public information. Moreover if we consider the case of adverse selection with endogenous heterogeneity, the well being of type $L$ individuals deteriorates relative to the case of pure moral hazard equilibrium. Furthermore note that the self-selection constraint is satisfied: the utility level of type $H$ individuals wouldn't increase if they purchased the separating contract designed for type $L$ individuals.

In case of separating equilibrium there are the inefficiency caused by moral hazard and the negative externality caused by adverse selection. The fact that firms consider the possibility that individuals modify the investment in health care in the first period in response to separating contracts offered to them breeds the inefficiency $V^{i}\left(\tilde{\mathbf{x}}^{i}\right)<V^{i}\left(\mathbf{x}^{i}\right)$ for $i=L, H$. This inefficiency is purely destructive: both members of group $L$ and members of group $H$ are worse off than they would be in case of public information. The presence of agents of group $H$ exerts a negative externality on agents of group $L: V^{L}\left(\check{\mathbf{x}}^{L}\right)<$ $V^{L}\left(\tilde{\mathbf{x}}^{L}\right)$. This negative externality is not purely destructive because members of group $L$ are worse off than they would be in case of pure moral hazard equilibrium, but members of group $H$ are not.

\section{Pooling Contract}

Before analysing the pooling contract in our model, it is convenient to remind the previous literature results, i.e. the non-existence of a RothschildStiglitz pooling equilibrium versus the existence of a Wilson pooling equilibrium. 
According to Rothschild and Stiglitz (1976) there always exists some contract $A$ close to the pooling contract $F$ which, if offered, is preferred by members of group $L$, but not by members of group $H$ (see figure 1 ). The contract $A$ will be exclusively bought by members of group $L$ and therefore if a firm offers this contract will earn non-negative profits. The second part of the definition of an equilibrium by Rothschild and Stiglitz (1976) states that there is no contract outside the equilibrium set that, if offered, will make a non-negative profit. Hence the pooling equilibrium $F$ does not exist (see Appendix).

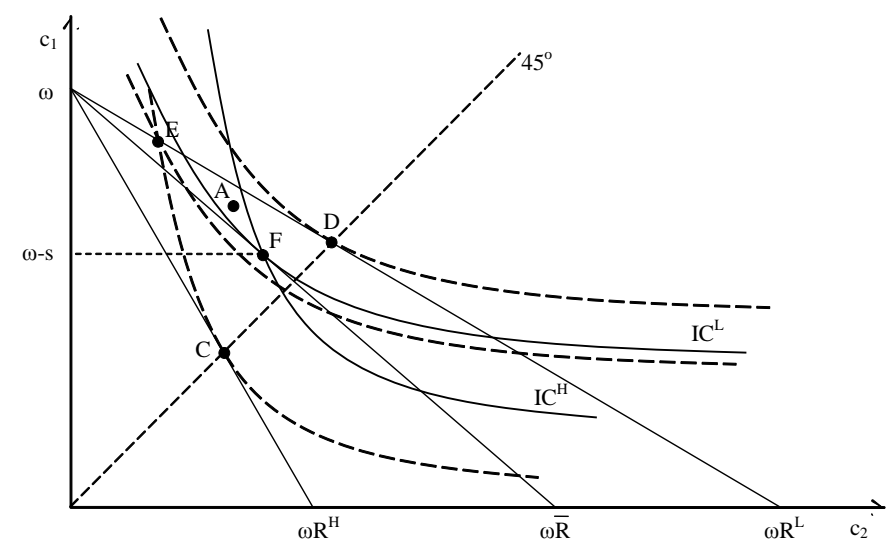

Figure 1. The Wilson Pooling Equilibrium

Wilson (1977) solves the problems of non-existence of a Rothschild-Stiglitz equilibrium in a contest in which firms carry on accomplishing a screening strategy. Each firm will correctly anticipate which of those policies that are offered by other firms will become unprofitable as a consequence of any change in its own policies. Then a firm offers a new policy only if it makes nonnegative profits after all the other firms have made the expected adjustment in their policy offers. In the specific case, if a firm tried to break the pooling equilibrium by offering the contract $A$ (see figure 1), type $L$ individuals would purchase this contract. Since the contract $F$ would now attract only type $H$ individuals, it would make negative profits and hence all the other firms would drop the contract $F$ and would offer the contract $A$. But if the contract $A$ were purchased by members of both groups, then this contract would make negative profits. Therefore no firm offers the contract $A$ and the pooling equilibrium $F$ does exist.

Hence in the following we will adopt the Wilson (1977)'s definition of an equilibrium.

With private information firms don't know whether any particular individual belongs to group $L$ or $H$. Then if we consider the possibility of crosssubsidization across different types, firms offer to members of both groups not only the same rate of return, but also the same premium: a pooling contract is characterized not only by $R^{L}=R^{H}=\bar{R}$, but also by $s^{L}=s^{H}=\bar{s}$. Then the zero profits condition expressed in terms of rate of return of pooling contract 
is, with $\overline{\mathbf{h}}=\left(\bar{h}^{L}, \bar{h}^{H}\right)$,

$$
R(\overline{\mathbf{h}})=\frac{1+\gamma}{\pi\left(\bar{h}^{L}\right)+\gamma \pi\left(\bar{h}^{H}\right)}
$$

Suppose that annuity supplying firms offer a pooling contract characterized by a premium $\bar{s}$ that doesn't maximize the utility of individuals of group $L$. Given this case, if a firm offered a pooling contract characterized by a premium $\bar{s}$ that maximized the utility of individuals of group $L$, individuals of this group would purchase this second contract and the profits of firms that offered the first contract would become negative (see, e.g., Wilson (1977)). Thus the pooling equilibrium will maximize the utility of type $L$ individuals subject to the zero profits condition (45).

Rephrasing in terms of net endowments available to the individuals in the two periods

$$
\begin{aligned}
& \bar{x}_{1}=\omega-\bar{s} \\
& \bar{x}_{2}=\bar{s} R(\overline{\mathbf{h}})
\end{aligned}
$$

we can write

$$
\bar{x}_{1}+\frac{1}{R(\overline{\mathbf{h}})} \bar{x}_{2}=\omega
$$

Because individuals can take hidden actions to affect their longevity, competitive firms offer to members of group $L$ the utility-maximizing actuarially fair pooling annuity contract $\overline{\mathbf{x}}$ (see, e.g., Eckstein, Eichenbaum and Peled (1985)) given that individuals belonging to both groups choose the optimal level of $h$ in response to this pooling contract (see maximization problem (11)) - implicit incentive constraints (see, e.g., Davies and Kuhn (1992)).

Then the maximization problem in case of pooling contract with private information is

$$
\begin{array}{ll}
\max _{\overline{\mathbf{x}}} & V^{L}(\overline{\mathbf{x}}) \\
\text { s.t. } & \bar{x}_{1}+\left(\frac{\pi\left(h^{L}(\overline{\mathbf{x}})\right)+\gamma \pi\left(h^{H}(\overline{\mathbf{x}})\right)}{1+\gamma}\right) \bar{x}_{2}=\omega\left(\lambda^{L}\right)
\end{array}
$$

After formulating the $\mathcal{L}$ agrangian, by using the equations (16) and (17) to replace $V_{1}^{i}$ and $V_{2}^{i}$ and the short-hands $\bar{h}^{i}=h^{i}(\overline{\mathbf{x}}), \bar{c}^{i}=c\left(h^{i}(\overline{\mathbf{x}})\right)$ and $\bar{\pi}^{i}=$ $\pi\left(h^{i}(\overline{\mathbf{x}})\right)$ we obtain the Euler equation that applies in case of pooling contract

$$
\frac{u^{\prime}\left(\bar{x}_{1}-\bar{c}^{L}\right)}{u^{\prime}\left(\bar{x}_{2}\right)}=\beta^{L} \frac{(1+\gamma)\left(1+\frac{\pi^{\prime}}{c^{\prime}} \bar{x}_{2}\right)}{\left(1+\gamma \frac{\bar{\pi}^{H}}{\bar{\pi}^{L}}\right)+\left(\frac{h_{2}^{L}}{\bar{h}^{L}}+\gamma \frac{h_{2}^{H}}{\bar{h}^{L}}\right) \bar{x}_{2}}
$$


where $h_{2}^{L}$ and $h_{2}^{H}$ are defined in (20). With respect to type $H$ individuals we have

$$
V^{H}(\overline{\mathbf{x}})>V^{H}\left(\tilde{\mathbf{x}}^{H}\right)
$$

since $R(\overline{\mathbf{h}})>R\left(\tilde{h}^{H}\right)$. With respect to type $L$ individuals we can notice that the equation (49) converges to equation (30) whit $i=L$ when $\gamma=0$ and/or $\bar{h}^{L}=\bar{h}^{H}$. Then we can conclude that the utility of individual of group $L$ is higher in case of pooling contract than in case of separating contract

$$
V^{L}(\overline{\mathbf{x}})>V^{L}\left(\check{\mathbf{x}}^{L}\right)
$$

(i) if the number of type $H$ agents is relatively small with respect to the number of type $L$ agents ( $\gamma$ is small) and/or (ii) if the difference between the rates of time preference $\beta^{L}$ and $\beta^{H}$ is small (and then if the difference between the investments in health care $\bar{h}^{L}$ and $\bar{h}^{H}$ is small). In fact

(1) for small values of $\gamma$ (for a relatively small number of type $H$ agents) the decreasing effect on the rate of return of the pooling contract $R(\overline{\mathbf{h}})$ caused by the existence of individuals of group $H$ is small $-R(\overline{\mathbf{h}})$ is relatively large,

(2) if the difference between the rates of time preference $\beta^{L}$ and $\beta^{H}$ is small the effect of the survival probability of type $H$ agents $\pi\left(h^{H}\right)$ on the rate of return of the pooling contract $R(\overline{\mathbf{h}})$ is small - $R(\overline{\mathbf{h}})$ is relatively large.

If the number of type $H$ agents is small with respect to the number of type $L$ agents ( $\gamma$ is small) in relation with the difference between the rates of time preference $\beta^{L}$ and $\beta^{H}$, then not only $V^{H}(\overline{\mathbf{x}})>V^{H}\left(\tilde{\mathbf{x}}^{H}\right)$ but also $V^{L}(\overline{\mathbf{x}})>V^{L}\left(\check{\mathbf{x}}^{L}\right)$ : members of group $L$ as well as members of group $H$ prefer the pooling contract to the separating contracts and the pooling equilibrium occurs.

On the contrary if the number of type $H$ agents is relatively large with respect to the number of type $L$ agents ( $\gamma$ is relatively big) in relation with the difference between the rates of time preference $\beta^{L}$ and $\beta^{H}$, then $V^{H}(\overline{\mathbf{x}})>$ $V^{H}\left(\tilde{\mathbf{x}}^{H}\right)$ but $V^{L}(\overline{\mathbf{x}})<V^{L}\left(\check{\mathbf{x}}^{L}\right)$ : members of group $H$ prefer the pooling contract to the separating contract but members of group $L$ don't and the separating equilibrium occurs.

In the simulation (see table 2 ) the pooling equilibrium happens for $\beta^{L}=0.3$ and $\beta^{H}=1.0$ if $\gamma<0.15-V^{L}(\overline{\mathbf{x}})(6.9302)>V^{L}\left(\check{\mathbf{x}}^{L}\right)(6.9295)$, for $\beta^{L}=0.4$ and $\beta^{H}=0.9$ if $\gamma<0.40-V^{L}(\overline{\mathbf{x}})(7.0728)>V^{L}\left(\check{\mathbf{x}}^{L}\right)(7.0673)$, for $\beta^{L}=0.5$ and $\beta^{H}=0.8$ if $\gamma<0.80-V^{L}(\overline{\mathbf{x}})(7.2821)>V^{L}\left(\check{\mathbf{x}}^{L}\right)(7.2819)$ - and for $\beta^{L}=0.6$ and $\beta^{H}=0.7$ if $\gamma<2.00-V^{L}(\overline{\mathbf{x}})(7.5517)>V^{L}\left(\check{\mathbf{x}}^{L}\right)(7.5516)$; consequently the separating equilibrium happens for $\beta^{L}=0.3$ and $\beta^{H}=1.0$ if $\gamma \geq 0.15-V^{L}(\overline{\mathbf{x}})(6.9261)<V^{L}\left(\check{\mathbf{x}}^{L}\right)(6.9295)$, for $\beta^{L}=0.4$ and $\beta^{H}=0.9$ if $\gamma \geq 0.40-V^{L}(\overline{\mathbf{x}})(7.0659)<V^{L}\left(\check{\mathbf{x}}^{L}\right)(7.0673)$, for $\beta^{L}=0.5$ and $\beta^{H}=0.8$ 
if $\gamma \geq 0.80-V^{L}(\overline{\mathbf{x}})(7.2811)<V^{L}\left(\check{\mathbf{x}}^{L}\right)(7.2819)-$ and for $\beta^{L}=0.6$ and $\beta^{H}=0.7$ if $\gamma \geq 2.00-V^{L}(\overline{\mathbf{x}})(7.5512)<V^{L}\left(\check{\mathbf{x}}^{L}\right)(7.5516)$.

So, to summarize the findings so far, in case of pooling equilibrium there are the inefficiency caused by moral hazard and the negative externality caused by the presence of individuals of group $H$. The fact that firms consider the possibility that members of all groups modify the investment in health care in the first period in response to the pooling contract offered to them breeds an inefficiency. In principle this inefficiency can be considered purely destructive. The presence of individuals of group $H$ exerts a negative externality on agents of group $L$ because $\pi\left(h^{H}\right)>\pi\left(h^{L}\right)$ and then $R(\overline{\mathbf{h}})<R\left(h^{L}\right)$. If individuals $L$ and $H$ are sufficiently heterogeneous, this negative externality is not purely destructive because while members of group $L$ are worse off than they would be in absence of private information $V^{L}(\overline{\mathbf{x}})<V^{L}\left(\mathbf{x}^{L}\right)$, members of group $H$ are better off $V^{H}(\overline{\mathbf{x}})>V^{H}\left(\mathbf{x}^{H}\right)$. Hence when a pooling contract is offered by the annuity supplying firms, for members of group $H$ the inefficiency caused by moral hazard is completely compensated by $R(\overline{\mathbf{h}})>R\left(h^{H}\right)$.

Table 2. Pooling Contract and Separating Contracts

\begin{tabular}{|c|c|c|c|c|c|c|}
\hline \multirow[b]{2}{*}{$\beta^{L}=0.3-\beta^{H}=1.0$} & \multicolumn{2}{|c|}{ Public } & \multicolumn{2}{|c|}{ Separating } & \multicolumn{2}{|c|}{ Pooling } \\
\hline & $L$ & $H$ & $L$ & $H$ & $L^{\gamma=0.09}{ }_{H}$ & $L^{\gamma=0.15} H$ \\
\hline $\begin{array}{l}\bar{s} \\
s^{i}\end{array}$ & 45.39 & 142.74 & 22.34 & 144.06 & 46.84 & 46.71 \\
\hline $\bar{R}$ & נד. & & & & 3.10 & 2.95 \\
\hline$R^{i}$ & 4.98 & 1.58 & 4.14 & 1.49 & & \\
\hline$V^{i}$ & 6.9517 & 8.8426 & 6.9295 & 8.8240 & 6.93029 .0482 & $\begin{array}{ll}6.9261 & 9.0099\end{array}$ \\
\hline$\beta^{L}=0.4-\beta^{H}=0.9$ & $L$ & $H$ & $L$ & $H$ & $\begin{array}{c}\gamma=0.25 \\
L\end{array}$ & $L^{\gamma=0.40} \quad H$ \\
\hline $\begin{array}{l}\bar{s} \\
s_{-}^{i}\end{array}$ & 80.16 & 138.10 & 44.89 & 139.56 & 83.66 & 84.04 \\
\hline $\begin{array}{l}\bar{R} \\
D^{i}\end{array}$ & & & & & 2.06 & 1.98 \\
\hline $\begin{array}{l}R^{i} \\
V^{i}\end{array}$ & $\begin{array}{c}2.82 \\
7.1061\end{array}$ & $\begin{array}{c}1.64 \\
8.5059\end{array}$ & $\begin{array}{c}2.38 \\
7.0673\end{array}$ & $\begin{array}{c}1.53 \\
8.4874\end{array}$ & $\begin{array}{lll}7.0728 & 8.6217\end{array}$ & 7.06598 .5975 \\
\hline$\beta^{L}=0.5-\beta^{H}=0.8$ & $L$ & $H$ & $L$ & $H$ & $\begin{array}{r}\gamma=0.75 \\
H\end{array}$ & $L^{\gamma=0.80} H$ \\
\hline $\begin{array}{l}s \\
s^{i} \\
\bar{R}\end{array}$ & 101.02 & 132.31 & 64.03 & 133.92 & 1.75 & 1.74 \\
\hline $\begin{array}{l}R^{i} \\
V^{i}\end{array}$ & $\begin{array}{c}2.24 \\
7.3251\end{array}$ & $\begin{array}{c}1.71 \\
8.1815\end{array}$ & $\begin{array}{c}1.92 \\
7.2819\end{array}$ & $\begin{array}{c}1.58 \\
8.1632\end{array}$ & 7.28218 .2110 & 7.28118 .2091 \\
\hline$\beta^{L}=0.6-\beta^{H}=0.7$ & $L$ & $H$ & $L$ & $H$ & $\begin{array}{r}\gamma=1.80 \\
H\end{array}$ & $L^{\gamma=2.00} H$ \\
\hline $\begin{array}{l}s^{i} \\
\bar{R} \\
R^{i}\end{array}$ & 114.92 & 124.86 & 86.94 & 126.66 & 1.68 & 1.68 \\
\hline $\begin{array}{l}R^{i} \\
V^{i}\end{array}$ & $\begin{array}{c}1.97 \\
7.5849 \\
\end{array}$ & $\begin{array}{c}1.81 \\
7.8729\end{array}$ & $\begin{array}{c}1.72 \\
7.5516\end{array}$ & $\begin{array}{c}1.65 \\
7.8548\end{array}$ & 7.55177 .8640 & 7.55127 .8633 \\
\hline
\end{tabular}

In table 2 when $\beta^{L}=0.3$ and $\beta^{H}=1.0$ we have $R\left(h^{H}\right)(1.58)<R(\overline{\mathbf{h}})(3.10)<$ $R\left(h^{L}\right)(4.98)$ and then $V^{L}(\overline{\mathbf{x}})(6.9295)<V^{L}\left(\mathbf{x}^{L}\right)(6.9517)$ and $V^{H}(\overline{\mathbf{x}})(6.9295)>$ 
$V^{H}\left(\mathbf{x}^{H}\right)(6.9517)$, when $\beta^{L}=0.4$ and $\beta^{H}=0.9$ we have $R\left(h^{H}\right)(1.64)<$ $R(\overline{\mathbf{h}})(2.06)<R\left(h^{L}\right)(2.82)$ and then $V^{L}(\overline{\mathbf{x}})(7.0728)<V^{L}\left(\mathbf{x}^{L}\right)(7.1061)$ and $V^{H}(\overline{\mathbf{x}})(8.6217)>V^{H}\left(\mathbf{x}^{H}\right)(8.5059)$ and when $\beta^{L}=0.5$ and $\beta^{H}=0.8$ we have $R\left(h^{H}\right)(1.71)<R(\overline{\mathbf{h}})(1.75)<R\left(h^{L}\right)(2.24)$ and then $V^{L}(\overline{\mathbf{x}})(7.2821)<$ $V^{L}\left(\mathbf{x}^{L}\right)(7.3251)$ and $V^{H}(\overline{\mathbf{x}})(8.2110)>V^{H}\left(\mathbf{x}^{H}\right)$ (8.1815). On the contrary, when $\beta^{L}=0.6$ and $\beta^{H}=0.7$, i.e. individuals $L$ and $H$ are not sufficiently heterogeneous, we have $R(\overline{\mathbf{h}})(1.68)<R\left(h^{H}\right)(1.81)<R\left(h^{L}\right)(1.97)$ and then $V^{L}(\overline{\mathbf{x}})(7.5517)<V^{L}\left(\mathbf{x}^{L}\right)(7.5849)$ and $V^{H}(\overline{\mathbf{x}})(7.8640)<V^{H}\left(\mathbf{x}^{H}\right)(7.8729)$.

\section{Mandatory Social Security}

Since both in separating equilibrium and in pooling equilibrium there are inefficiencies and negative externalities, the investigation of possible Pareto improving policies which the Social Planner can implement is interesting.

The government may regulate the annuity market by imposing restrictions on the annuity contract terms or by imposing taxes and/or subsidies, measures more suitable to bound the externality caused by adverse selection than the inefficiency caused by moral hazard. In reply directly to the moral hazard problem - and perhaps indirectly to the adverse selection problem - the government may also intervene in the health market. However, by introducing a mandatory annuity programme, the government may simultaneously reduce the inefficiencies arising from moral hazard and the negative externalities arising from adverse selection.

Eckstein, Eichenbaum and Peled (1985) have argued that a mandatory social security programme undertaken by a Social Planner can have positive effects on welfare when individuals possess hidden information about their longevity (the annuity market is affected by adverse selection). In particular they have shown that an initial pooling equilibrium can always be Pareto dominated by a public programme, while an initial separating equilibrium dominates or is dominated by such a programme. On the contrary, Davies and Kuhn (1992) have shown that social security never raises welfare in a pure moral hazard economy, i.e. in an economy where individuals can take hidden actions to affect their longevity by consuming "health-related goods".

The search for allocations which dominate those obtained as competitive equilibria requires that (i) all agents purchase a given amount $s_{S}$ of public provided annuity that pays a rate of return $R_{S}$ (hence the public provided annuity is a pooling contract) and that (ii) agents can satisfy the residual demand for annuities in the private market where competitive firms offer separating contracts $\left(s_{S}^{i}, R_{S}^{i}\right)$, with $i=L, H$.

When the same premium at the same rate of return is offered to members of both groups the zero profits condition expressed in terms of rate of return 
of public provided annuity, with $\mathbf{h}_{\mathbf{S}}=\left(h_{S}^{L}, h_{S}^{H}\right)$, is

$$
R\left(\mathbf{h}_{\mathbf{S}}\right)=\frac{1+\gamma}{\pi\left(h_{S}^{L}\right)+\gamma \pi\left(h_{S}^{H}\right)}
$$

With $s_{S}$ the premium paid to public provided annuity - equal for both individual types - and $s_{S}^{i}$ for $i=L, H$ the premiums paid in the private market, the net endowments available to the individuals in the two periods are

$$
\begin{aligned}
& x_{S, 1}^{i}=\omega-s_{S}^{i}-s_{S} \\
& x_{S, 2}^{i}=s_{S}^{i} R_{S}^{i}+s_{S} R_{S}
\end{aligned}, i=L, H
$$

In a separating equilibrium the damage - inefficiency and negative externality - suffered by type $L$ individuals are larger than the damage - inefficiency - suffered by type $H$ individuals. In a pooling equilibrium while members of groups $L$ are worse off than they would be in case of competitive equilibrium with public information, members of groups $H$ are better off.

The Social Planner and the competitive firms respectively offer to members of group $L$ the mandatory pooling contract $\left(s_{S}, R_{S}\right)$ and the separating

contract $\left(s_{S}^{L}, R_{S}^{L}\right)$, and then they offer to members of group $L$ the utilitymaximizing actuarially fair annuity contract $\mathbf{x}_{S}^{L}$ (i) given that type $L$ and type $H$ individuals choose the optimal level of $h$ in response to contracts offered to them (see maximization problem (11)) - implicit incentive constraint (see, e.g., Davies and Kuhn (1992)) and (ii) subject to the constraint that the contract designed for members of group $L$ must not be more attractive to members of group $H$ than contract $\mathbf{x}_{S}^{H}$ - incentive-compatibility or self-selection constraint (see, e.g., Eckstein, Eichenbaum and Peled (1985)).

Thus in the following we will consider both an initial separating equilibrium and an initial pooling equilibrium.

\section{Initial Separating Equilibrium}

If we analyse an initial separating equilibrium, we should consider that the introduction of a public provided annuity reduces the volume of the original separating contracts, now purchased only to satisfy the residual demand for annuities. The magnitude of this reduction depends on the volume of the public provided annuity $\left(s_{S}, R_{S}\right)$. Hence we should rewrite the net endowments (51) as

$$
\begin{aligned}
& x_{S, 1}^{L}+\pi\left(h_{S}^{L}\right) x_{S, 2}^{L}+\gamma \frac{\pi\left(h_{S}^{H}\right)-\pi\left(h_{S}^{L}\right)}{\pi\left(h_{S}^{L}\right)+\gamma \pi\left(h_{S}^{H}\right)} s_{S}=\omega \\
& x_{S, 1}^{H}+\pi\left(h_{S}^{H}\right) x_{S, 2}^{H}-\frac{\pi\left(h_{S}^{H}\right)-\pi\left(h_{S}^{L}\right)}{\pi\left(h_{S}^{L}\right)+\gamma \pi\left(h_{S}^{H}\right)} s_{S}=\omega
\end{aligned}
$$

By considering the net endowments (52) the maximization problem from an 
initial separating equilibrium is

$$
\begin{array}{ll}
\max _{\mathbf{x}_{S}^{L}, \mathbf{x}_{S}^{H}, s_{S}} & V^{L}\left(\mathbf{x}_{S}^{L}\right) \\
\text { s.t. } & x_{S, 1}^{L}+\pi\left(h\left(\mathbf{x}_{S}^{L}\right)\right) x_{S, 2}^{L}+\gamma \frac{\pi\left(h\left(\mathbf{x}_{S}^{H}\right)\right)-\pi\left(h\left(\mathbf{x}_{S}^{L}\right)\right)}{\pi\left(h\left(\mathbf{x}_{S}^{L}\right)\right)+\gamma \pi\left(h\left(\mathbf{x}_{S}^{H}\right)\right)} s_{S}=\omega\left(\lambda^{L}\right) \\
& x_{S, 1}^{H}+\pi\left(h\left(\mathbf{x}_{S}^{H}\right)\right) x_{S, 2}^{H}-\frac{\pi\left(h\left(\mathbf{x}_{S}^{H}\right)\right)-\pi\left(h\left(\mathbf{x}_{S}^{L}\right)\right)}{\pi\left(h\left(\mathbf{x}_{S}^{L}\right)\right)+\gamma \pi\left(h\left(\mathbf{x}_{S}^{H}\right)\right)} s_{S}=\omega\left(\lambda^{H}\right) \\
& V^{H}\left(\mathbf{x}_{S}^{H}\right) \geq \hat{V}^{H}\left(\mathbf{x}_{S}^{L}\right)(\sigma)
\end{array}
$$

The FOCs of the maximization problem (53) are

$$
\begin{gathered}
\frac{\partial \mathcal{L}}{\partial x_{S, 1}^{L}=} u^{\prime}\left(x_{S, 1}^{L}-c_{S}^{L}\right)-\sigma u^{\prime}\left(x_{S, 1}^{L}-c_{S}^{H}\right)-\lambda^{L}\left(1+\frac{\pi^{\prime}}{c^{\prime}} x_{S, 2}^{L}\right)+ \\
-\left(\lambda^{H}-\lambda^{L} \gamma\right) \frac{\pi^{\prime}}{c^{\prime}} \frac{(1+\gamma) \pi_{S}^{H}}{\left(\pi_{S}^{L}+\gamma \pi_{S}^{H}\right)^{2}} s_{S}=0 \\
\frac{\partial \mathcal{L}}{\partial x_{S, 2}^{L}}=\left(\beta^{L} \pi_{S}^{L}-\sigma \beta^{H} \pi_{S}^{H}\right) u^{\prime}\left(x_{S, 2}^{L}\right)-\lambda^{L}\left(\pi_{S}^{L}+\pi^{\prime} h_{2}^{L} x_{S, 2}^{L}\right)+ \\
-\left(\lambda^{H}-\lambda^{L} \gamma\right) \pi^{\prime} h_{2}^{L} \frac{(1+\gamma) \pi_{S}^{H}}{\left(\pi_{S}^{L}+\gamma \pi_{S}^{H}\right)^{2}} s_{S}=0 \\
\frac{\partial \mathcal{L}}{\partial x_{S, 1}^{H}}=\sigma u^{\prime}\left(x_{S, 1}^{H}-c_{S}^{H}\right)-\lambda^{H}\left(1+\frac{\pi^{\prime}}{c^{\prime}} x_{S, 2}^{H}\right)+ \\
+\left(\lambda^{H}-\lambda^{L} \gamma\right) \frac{\pi^{\prime}}{c^{\prime}} \frac{(1+\gamma) \pi_{S}^{L}}{\left(\pi_{S}^{L}+\gamma \pi_{S}^{H}\right)^{2}} s_{S}=0 \\
\frac{\partial \mathcal{L}}{\partial x_{S, 2}^{H}}=\sigma \beta^{H} \pi_{S}^{H} u^{\prime}\left(x_{S, 2}^{H}\right)-\lambda^{H}\left(\pi_{S}^{H}+\pi^{\prime} h_{2}^{H} x_{S, 2}^{L}\right)+ \\
+\left(\lambda^{H}-\lambda^{L} \gamma\right) \pi^{\prime} h_{2}^{H} \frac{(1+\gamma) \pi_{S}^{L}}{\left(\pi_{S}^{L}+\gamma \pi_{S}^{H}\right)^{2}} s_{S}=0 \\
\frac{\partial \mathcal{L}}{\partial s_{S}}=\left(\lambda^{H}-\lambda^{L} \gamma\right) \frac{\pi_{S}^{H}-\pi_{S}^{L}}{\pi_{S}^{L}+\gamma \pi_{S}^{H}}=0
\end{gathered}
$$

From the FOC (58) it is obvious that

$$
\lambda^{H}=\gamma \lambda^{L}
$$

and then the last element of all the FOCs drops out; hence we obtain the equations (43) and (44) characterizing the separating contracts

$$
\frac{u^{\prime}\left(x_{S, 1}^{H}-c_{S}^{H}\right)}{u^{\prime}\left(x_{S, 2}^{H}\right)}=\beta^{H} \frac{\left(1+\frac{\pi^{\prime}}{c^{\prime}} x_{S, 2}^{H}\right)}{\left(1+\frac{h_{2}^{H}}{h_{S}^{H}} x_{S, 2}^{H}\right)}
$$


and

$$
\frac{u^{\prime}\left(x_{S, 1}^{L}-c_{S}^{L}\right)-\sigma u^{\prime}\left(x_{S, 1}^{L}-\hat{c}_{S}^{H}\right)}{\left(1-\sigma \frac{\beta^{H}}{\beta^{L}} \frac{\hat{\pi}_{S}^{H}}{\pi_{S}^{L}}\right) u^{\prime}\left(x_{S, 2}^{L}\right)}=\beta^{L} \frac{\left(1+\frac{\pi^{\prime}}{c^{\prime}} x_{S, 2}^{L}\right)}{\left(1+\frac{h_{2}^{L}}{h_{S}^{L}} x_{S, 2}^{L}\right)}
$$

The Social Planner will implement a public provided annuity if this will increase the well-being of type $L$ individuals. The introduction of this mandatory pooling contract will affect the existing private separating contracts and the investment behaviours of all individual types. Specifically $d s_{S}>0$ (from zero to $s_{S}$ ) implies $d s_{S}^{L}<0$ (from $\check{s}^{L}$ to $s_{S}^{L}$ ) and from the derivatives (19) and (20) we know that $d h_{S}^{L}>0$ (from $\check{h}^{L}$ to $h_{S}^{L}$ ), and hence that $d R_{S}^{L}<0$ (from $\check{R}^{L}$ to $R_{S}^{L}$ ) and $d R_{S}<0$ (from $\bar{R}$ - not active - to $R_{S}$ ). Then if we consider an initial separating equilibrium the variation of the expected utility of type $L$ individuals is

$$
\begin{aligned}
& d V^{L}=V_{1}^{L}\left(\underset{-}{-d s_{S}-d s_{S}^{L}-c^{\prime} \cdot d h_{S}^{L}}\right)+
\end{aligned}
$$

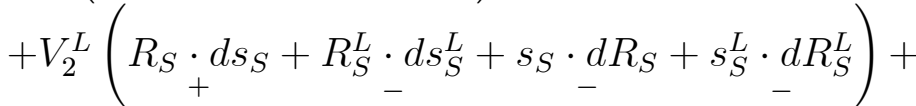

$$
\begin{aligned}
& \begin{array}{c}
+\beta^{L} \pi^{\prime} \cdot d h_{S}^{L} \cdot u\left(x_{S, 2}^{L}\right) \\
+
\end{array}
\end{aligned}
$$

where $V_{1}^{L}$ and $V_{2}^{L}$ are defined respectively in (16) and (17). The separating equilibrium is Pareto dominated by the public programme if $d V^{L}>0$, and then if

$$
\begin{aligned}
& -d s_{S}^{L} \cdot V_{1}^{L}+R_{S} \cdot d s_{S} \cdot V_{2}^{L}+\beta^{L} \pi^{\prime} \cdot d h_{S}^{L} \cdot u\left(x_{S, 2}^{L}\right) \\
& V_{1}^{L}\left(d s_{S}+c^{\prime} \cdot d h_{S}^{L}\right)+V_{2}^{L}\left(-R_{S}^{L} \cdot d s_{S}^{L}-s_{S} \cdot d R_{S}-s_{S}^{L} \cdot d R_{S}^{L}\right)
\end{aligned}>
$$

The simulation (see table 3 ) shows that the utility of type $H$ individuals is always higher in case of Social Planner intervention than in case of separating equilibrium

$$
V^{H}\left(\mathbf{x}_{S}^{H}\right)>V^{H}\left(\tilde{\mathbf{x}}^{H}\right)
$$

because the rate of return of the public provided annuity is strictly higher than the rate of return offered in the private market to type $H$ agents $R\left(\mathbf{h}_{\mathbf{S}}\right)>$ $R\left(\tilde{h}^{H}\right)$ : when $\beta^{L}=0.3$ and $\beta^{H}=1.0$ if $\gamma=0.15$ since $R\left(\mathbf{h}_{\mathbf{S}}\right)(3.20)>$ $R\left(\tilde{h}^{H}\right)(1.46)$ we have $V^{H}\left(\mathbf{x}_{S}^{H}\right)(8.8998)>V^{H}\left(\tilde{\mathbf{x}}^{H}\right)(8.8240)$ and when $\beta^{L}=$ 0.6 and $\beta^{H}=0.7$ if $\gamma=2.00$ since $R\left(\mathbf{h}_{\mathbf{S}}\right)(1.677)>R\left(\tilde{h}^{H}\right)(1.65)$ we have $V^{H}\left(\mathbf{x}_{S}^{H}\right)(7.8605)>V^{H}\left(\tilde{\mathbf{x}}^{H}\right)(7.8548)$.

The simulation (see table 3 ) shows also that the utility of individual of group $L$ is higher in case of public programme than in case of separating equilibrium

$$
V^{L}\left(\mathbf{x}_{S}^{L}\right)>V^{L}\left(\check{\mathbf{x}}^{L}\right)
$$


if the number of type $H$ agents is not too large with respect to the number of type $L$ agents ( $\gamma$ is not too big) in relation with the difference between the rates of time preference $\beta^{L}$ and $\beta^{H}$ : for $\beta^{L}=0.3$ and $\beta^{H}=1.0$ if $0.15 \leq \gamma<0.18$ - if $\gamma=0.15$ we have $V^{L}\left(\mathbf{x}_{S}^{L}\right)(6.9298)>V^{L}\left(\check{\mathbf{x}}^{L}\right)(6.9295)$ - and for $\beta^{L}=0.6$ and $\beta^{H}=0.7$ if $2.00 \leq \gamma<3.40-$ if $\gamma=2.00$ we have $V^{L}\left(\mathbf{x}_{S}^{L}\right)(7.5525)>$ $V^{L}\left(\check{\mathbf{x}}^{L}\right)(7.5516)$.

Table 3. Separating Equilibrium and Social Planner

\begin{tabular}{|c|c|c|c|c|c|c|}
\hline \multirow[b]{2}{*}{$\beta^{L}=0.3-\beta^{H}=1.0$} & \multicolumn{2}{|c|}{ Public } & \multicolumn{2}{|c|}{ Separating } & \multicolumn{2}{|c|}{ Social Planner } \\
\hline & $L$ & $H$ & $L$ & $H$ & $L^{\gamma=0.15}{ }_{H}$ & $L^{\gamma=0.18} H$ \\
\hline $\begin{array}{l}s_{S} \\
s^{i}, s_{S}^{i} \\
R_{S}\end{array}$ & 45.39 & 142 & 22.34 & 144.06 & $\begin{array}{c}14.43 \\
15.69 \quad 115.67 \\
3.20\end{array}$ & $\begin{array}{c}0 \\
22.34 \quad 144 . \\
3.26\end{array}$ \\
\hline $\begin{array}{l}R^{i}, R_{S}^{i} \\
V^{i}\end{array}$ & $\begin{array}{l}4.98 \\
6.9517\end{array}$ & & $\begin{array}{l}4.66 \\
6.9295\end{array}$ & & $\begin{array}{cc}3.89 & 1.46 \\
6.9298 & 8.8998\end{array}$ & $\begin{array}{cc}4.14 & 1.49 \\
6.9295 & 8.8240\end{array}$ \\
\hline$\beta^{L}=0.6-\beta^{H}=0.7$ & $L$ & & $L$ & $H$ & ${ }_{L}^{\gamma=2.00} H$ & ${ }_{L}^{\gamma=3.40} H$ \\
\hline $\begin{array}{l}s_{S} \\
s^{i}, s_{S}^{i} \\
R_{S}\end{array}$ & 114.92 & 124.86 & 86.94 & 126.66 & $\begin{array}{c}5.0327 .65 \\
1.677\end{array}$ & $\begin{array}{c}86.94126 .66 \\
1.67\end{array}$ \\
\hline $\begin{array}{l}R^{i}, R_{S}^{i} \\
V^{i}\end{array}$ & $\begin{array}{c}1.97 \\
7.5849 \\
\end{array}$ & $\begin{array}{c}1.81 \\
7.8729 \\
\end{array}$ & $\begin{array}{c}1.72 \\
7.5516\end{array}$ & $\begin{array}{c}1.65 \\
7.8548\end{array}$ & $\begin{array}{cc}1.74 & 1.65 \\
7.5525 & 7.8605\end{array}$ & $\begin{array}{cc}1.72 & 1.65 \\
7.5516 & 7.8548 \\
\end{array}$ \\
\hline
\end{tabular}

Hence if individuals are not largely heterogeneous both members of group $H$ and members of group $L$ prefer the public programme to the separating contracts. In other words, there is room for Social Planner to implement a Pareto improving policy if and only if individuals are not largely heterogeneous: if heterogeneity is large then the range of the relative size of two groups in which Social Planner can intervene is small, if heterogeneity is small then this range is large.

\section{Initial Pooling Equilibrium}

If we analyse an initial pooling equilibrium we should consider that the public provided annuity replaces the original pooling contract. Hence we should focus on the fact that type $L$ individuals have now the possibility to satisfy the residual demand for annuity by purchasing separating contract $\left(s_{S}^{L}, R_{S}^{L}\right)$ and rewrite the net endowments (51) as

$$
\begin{aligned}
& x_{S, 1}^{L}+\frac{\pi\left(h_{S}^{L}\right)+\gamma \pi\left(h_{S}^{H}\right)}{1+\gamma} x_{S, 2}^{L}-\frac{\gamma}{1+\gamma} \frac{\pi\left(h_{S}^{H}\right)-\pi\left(h_{S}^{L}\right)}{\pi\left(h_{S}^{L}\right)} s_{S}^{L}=\omega \\
& x_{S, 1}^{H}+\pi\left(h_{S}^{H}\right) x_{S, 2}^{H}-\frac{\pi\left(h_{S}^{H}\right)-\pi\left(h_{S}^{L}\right)}{\pi\left(h_{S}^{L}\right)}\left(x_{S, 2}^{L}-\frac{1}{1+\gamma} s_{S}^{L}\right)=\omega
\end{aligned}
$$

By considering the net endowments (64) the maximization problem from an 
initial pooling equilibrium is

$$
\begin{array}{ll}
\max _{\mathbf{x}_{S}^{L}, \mathbf{x}_{S}^{H}, s_{S}^{L}} V^{L}\left(\mathbf{x}_{S}^{L}\right) \\
\text { s.t. } & x_{S, 1}^{L}+\frac{\pi\left(h\left(\mathbf{x}_{S}^{L}\right)\right)+\gamma \pi\left(h\left(\mathbf{x}_{S}^{H}\right)\right)}{1+\gamma} x_{S, 2^{-}}^{L} \frac{\gamma}{1+\gamma} \frac{\pi\left(h\left(\mathbf{x}_{S}^{H}\right)\right)-\pi\left(h\left(\mathbf{x}_{S}^{L}\right)\right)}{\pi\left(h\left(\mathbf{x}_{S}^{L}\right)\right)} s_{S}^{L}=\omega\left(\lambda^{L}\right) \\
& x_{S, 1}^{H}+\pi\left(h_{S}^{H}\right) x_{S, 2^{-}}^{H} \frac{\pi\left(h\left(\mathbf{x}_{S}^{H}\right)\right)-\pi\left(h\left(\mathbf{x}_{S}^{L}\right)\right)}{\pi\left(h\left(\mathbf{x}_{S}^{L}\right)\right)}\left(x_{S, 2^{-}}^{L} \frac{1}{1+\gamma} s_{S}^{L}\right)=\omega\left(\lambda^{H}\right) \\
& V^{H}\left(\mathbf{x}_{S}^{H}\right) \geq \hat{V}^{H}\left(\mathbf{x}_{S}^{L}\right)(\sigma)
\end{array}
$$

The FOCs of the maximization problem (65) are

$$
\begin{gathered}
\frac{\partial \mathcal{L}}{\partial x_{S, 1}^{L}=} u^{\prime}\left(x_{S, 1}^{L}-c_{S}^{L}\right)-\lambda^{L}-\sigma u^{\prime}\left(x_{S, 1}^{L}-\hat{c}_{S}^{H}\right)+ \\
-\left(\lambda^{L}+\lambda^{H}\right) \frac{1}{1+\gamma} \frac{\pi^{\prime}}{c^{\prime}} x_{S, 2}^{L}+\left(\lambda^{H}-\gamma \lambda^{L}\right)\left(\frac{1}{1+\gamma} \frac{\pi^{\prime}}{c^{\prime}} \frac{\pi_{S}^{H}}{\pi_{S}^{L}} \frac{1}{\pi_{S}^{L}} s_{S}^{L}\right)=0 \\
\frac{\partial \mathcal{L}}{\partial x_{S, 2}^{L}=} \beta^{L} \pi_{S}^{L} u^{\prime}\left(x_{S, 2}^{L}\right)-\lambda^{L} \frac{\pi_{S}^{L}+\gamma \pi_{S}^{H}}{1+\gamma}+\lambda^{H} \frac{\pi_{S}^{H}-\pi_{S}^{L}}{1+\gamma}-\sigma \beta^{H} \hat{\pi}_{S}^{H} u^{\prime}\left(x_{S, 2}^{L}\right)+ \\
-\left(\lambda^{L}+\lambda^{H}\right) \frac{1}{1+\gamma} \pi^{\prime} h_{2}^{L} x_{S, 2}^{L}+\left(\lambda^{H}-\gamma \lambda^{L}\right)\left(\frac{1}{1+\gamma} \pi^{\prime} h_{2}^{L} \frac{\pi_{S}^{H}}{\pi_{S}^{L}} \frac{1}{\pi_{S}^{L}} s_{S}^{L}\right)=0 \\
\frac{\partial \mathcal{L}}{\partial x_{S, 1}^{H}}=-\lambda^{H}\left(1+\frac{\pi^{\prime}}{c^{\prime}} x_{S, 2}^{H}\right)+\sigma u^{\prime}\left(x_{S, 1}^{H}-c_{S}^{H}\right)+ \\
+\left(\lambda^{H}-\gamma \lambda^{L}\right) \frac{1}{1+\gamma} \frac{\pi^{\prime}}{c^{\prime}}\left(x_{S, 2}^{L}-\frac{1}{\pi_{S}^{L}} s_{S}^{L}\right)=0 \\
\frac{\partial \mathcal{L}}{\partial x_{S, 2}^{H}}=-\lambda^{H}\left(\pi_{S}^{H}+\pi^{\prime} h_{2}^{H} x_{S, 2}^{H}\right)+\sigma \beta^{H} \pi_{S}^{H} u^{\prime}\left(x_{S, 2}^{H}\right)+ \\
+\left(\lambda^{H}-\gamma \lambda^{L}\right) \frac{1}{1+\gamma} \pi^{\prime} h_{2}^{H}\left(x_{S, 2}^{L}-\frac{1}{\pi_{S}^{L}} s_{S}^{L}\right)=0 \\
\frac{\partial \mathcal{L}}{\partial s_{S}^{L}}=\left(\lambda^{H}-\lambda^{L} \gamma\right) \frac{1}{1+\gamma} \frac{\pi\left(h_{S}^{H}\right)-\pi\left(h_{S}^{L}\right)}{\pi\left(h_{S}^{L}\right)}=0
\end{gathered}
$$

From the $F O C(70)$ it is obvious that

$$
\lambda^{H}=\gamma \lambda^{L}
$$

and then the last element of all the FOCs drops out; hence we obtain the equations (43) and (44) characterizing the separating contracts

$$
\frac{u^{\prime}\left(x_{S, 1}^{H}-c_{S}^{H}\right)}{u^{\prime}\left(x_{S, 2}^{H}\right)}=\beta^{H} \frac{\left(1+\frac{\pi^{\prime}}{c^{\prime}} x_{S, 2}^{H}\right)}{\left(1+\frac{h_{2}^{H}}{h_{S}^{H}} x_{S, 2}^{H}\right)}
$$


and

$$
\frac{u^{\prime}\left(x_{S, 1}^{L}-c_{S}^{L}\right)-\sigma u^{\prime}\left(x_{S, 1}^{L}-\hat{c}_{S}^{H}\right)}{\left(1-\sigma \frac{\beta^{H}}{\beta^{L}} \frac{\hat{\pi}_{S}^{H}}{\pi_{S}^{L}}\right) u^{\prime}\left(x_{S, 2}^{L}\right)}=\beta^{L} \frac{\left(1+\frac{\pi^{\prime}}{c^{\prime}} x_{S, 2}^{L}\right)}{\left(1+\frac{h_{2}^{L}}{h_{S}^{L}} x_{S, 2}^{L}\right)}
$$

The Social Planner will substitute the existing pooling contract $(\bar{s}, \bar{R})$ with a public provided annuity $\left(s_{S}, R_{S}\right)$ characterized by $s_{S}<\bar{s}$ if the individuals (type $H$ and/or type $L$ ) have residual demand for annuity to satisfy in the private market: if this happens, the well-being of type $L$ individuals will increase. In fact Finkelstein (2002) has shown that the Pareto improving role for the government derives not from its unique capacity to compel participation in a public insurance programme, but from the fact that individuals may hold multiple insurance policies.

Hence in this case we have to consider the reduction of the premium of the pooling contract from the "private" level $\bar{s}$ to the "public" level $s_{S}$ combined with the introduction of separating contracts.

In evaluating the variation of the expected utility of type $L$ individuals it is important to consider also the effect of the residual demand for annuity of type $H$ individuals $s_{S}^{H}$ - computed from $x_{S, 1}^{H}$ in (51) given $s_{S}$ - on the rate of return of the public provided annuity $R_{S}$ : in fact, even if type $L$ individuals don't have a residual demand for annuity $d s_{S}^{L}=0$, the residual demand for annuity of type $H$ individuals $d s_{S}^{H}>0$ implies $d h_{S}^{H}<0$ and hence a higher rate of return of the public provided annuity $d R_{S}>0$.

Specifically $d s_{S}<0$ (from $\bar{s}$ to $s_{S}$ ) implies $d s_{S}^{L} \geq 0$ (from zero to $s_{S}^{L}$ ) and $d s_{S}^{H}>0$ (from zero to $s_{S}^{H}$ ) and from the derivatives (19) and (20) we know that $d h_{S}^{L}<0$ (from $\bar{h}^{L}$ to $h_{S}^{L}$ ) and $d h_{S}^{H}<0$ (from $\bar{h}^{H}$ to $h_{S}^{H}$ ), and hence that $d R_{S}^{L}>0$ (from $\bar{R}^{L}$ - not active - to $R_{S}^{L}$ ) and $d R_{S}>0$ (from $\bar{R}$ to $R_{S}$ ). Then if we consider an initial pooling equilibrium the variation of the expected utility of type $L$ individuals is

$$
\begin{aligned}
d V^{L}= & \left(\begin{array}{c}
-d s_{S}-d s_{S}^{L}-c^{\prime} \cdot d h_{S}^{L} \\
+
\end{array}\right) V_{1}^{L}+ \\
& +\left(\begin{array}{l}
R_{S} \cdot d s_{S}+R_{S}^{L} \cdot d s_{S}^{L}+s_{S} \cdot d R_{S}+\underset{+}{{ }_{(+)}}+d R_{S}^{L} \\
+(+)
\end{array}\right) V_{2}^{L}+ \\
& +\beta^{L} \pi^{\prime} \cdot d h_{S}^{L} \cdot u\left(x_{S, 2}^{L}\right)
\end{aligned}
$$

where $V_{1}^{L}$ and $V_{2}^{L}$ are defined respectively in (16) and (17). Members of group $L$ prefer the public programme (associated with private separating contracts) to the pooling contract if $d V^{L}>0$, and then if

$$
\begin{aligned}
& V_{1}^{L}\left(-d s_{S}-c^{\prime} \cdot d h_{S}^{L}\right)+V_{2}^{L}\left(R_{S}^{L} \cdot d s_{S}^{L}+s_{S} \cdot d R_{S}+s_{S}^{L} \cdot d R_{S}^{L}\right)> \\
& d s_{S}^{L} \cdot V_{1}^{L}-R_{S} \cdot d s_{S} \cdot V_{2}^{L}-\beta^{L} \pi^{\prime} \cdot d h_{S}^{L} \cdot u\left(x_{S, 2}^{L}\right)
\end{aligned}
$$


The simulation (see table 4) shows that while the utility of an individual of group $H$ is always lower in case of Social Planner intervention than in case of pooling contract, the utility of an individual of group $L$ is higher in case of Social Planner intervention than in case of pooling contract (i) if the difference between the rates of time preference $\beta^{L}$ and $\beta^{H}$ is not relatively small or small and (ii) if the number of type $H$ agents is not very small with respect to the number of type $L$ agents ( $\gamma$ is not very small).

The utility of individuals of group $H$ is always lower in case of mandatory social security than in case of pooling equilibrium

$$
V^{H}\left(\mathbf{x}_{S}^{H}\right)<V^{H}(\overline{\mathbf{x}})
$$

because $s_{S}<\bar{s}$ and the residual demand for annuities $s_{S}^{H}$ is satisfied in the private market but at a rate of return $R\left(h_{S}^{H}\right)<R\left(\mathbf{h}_{\mathbf{S}}\right)$ : for example when $\beta^{L}=$ 0.3 and $\beta^{H}=1.0$ if $\gamma=0.01$ with $s_{S}(44.42)<\bar{s}(46.92)$ and $R\left(h_{S}^{H}\right)(1.39)<$ $R\left(\mathbf{h}_{\mathbf{S}}\right)$ (3.36) we have $V^{H}\left(\mathbf{x}_{S}^{H}\right)(9.1036)<V^{H}(\overline{\mathbf{x}})(9.1070)$ and when $\beta^{L}=0.6$ and $\beta^{H}=0.7$ if $\gamma=1.80$ with $s_{S}(104.14)<\bar{s}(117.74)$ and $R\left(h_{S}^{H}\right)(1.65)<$ $R\left(\mathbf{h}_{\mathbf{S}}\right)(1.6798)$ we have $V^{H}\left(\mathbf{x}_{S}^{H}\right)(7.8615)<V^{H}(\overline{\mathbf{x}})(7.8640)$.

However, we already observed that if individuals $L$ and $H$ are sufficiently heterogeneous, the utility of type $H$ agents is higher in case of mandatory social security than in case of competitive equilibrium with public information

$$
V^{H}\left(\mathbf{x}_{S}^{H}\right)>V^{H}\left(\mathbf{x}^{H}\right)
$$

The well being of individuals of group $L$ can be analysed by considering two main scenarios. These agents have residual demand for annuities to satisfy in the private market

$$
s_{S}^{L}>0
$$

and then their utility is always higher in case of mandatory social security than in case of pooling equilibrium

- when the difference between the rates of time preference $\beta^{L}$ and $\beta^{H}$ is big, even if the number of type $H$ agents is very small with respect to the number of type $L$ agents (when $\beta^{L}=0.3$ and $\beta^{H}=1.0$ if $\gamma \leq 0.01-$ if $\gamma=0.01$ we have $\left.s_{S}^{L}=1.96\right)$,

- when the difference between the rates of time preference $\beta^{L}$ and $\beta^{H}$ is not big, if the number of type $H$ agents is not small with respect to the number of type $L$ agents (when $\beta^{L}=0.4$ and $\beta^{H}=0.9$ if $\gamma>0.12$ - if $\gamma=0.25$ we have $s_{S}^{L}=4.34$, when $\beta^{L}=0.5$ and $\beta^{H}=0.8$ if $\gamma>0.40-$ if $\gamma=0.75$ we have $s_{S}^{L}=10.59$ - and when $\beta^{L}=0.6$ and $\beta^{H}=0.7$ if $\gamma>1.70-$ if $\gamma=1.80$ we have $s_{S}^{L}=0.38$ ).

On the contrary, type $L$ agents don't have residual demand for annuities to satisfy in the private market

$$
s_{S}^{L}=0
$$




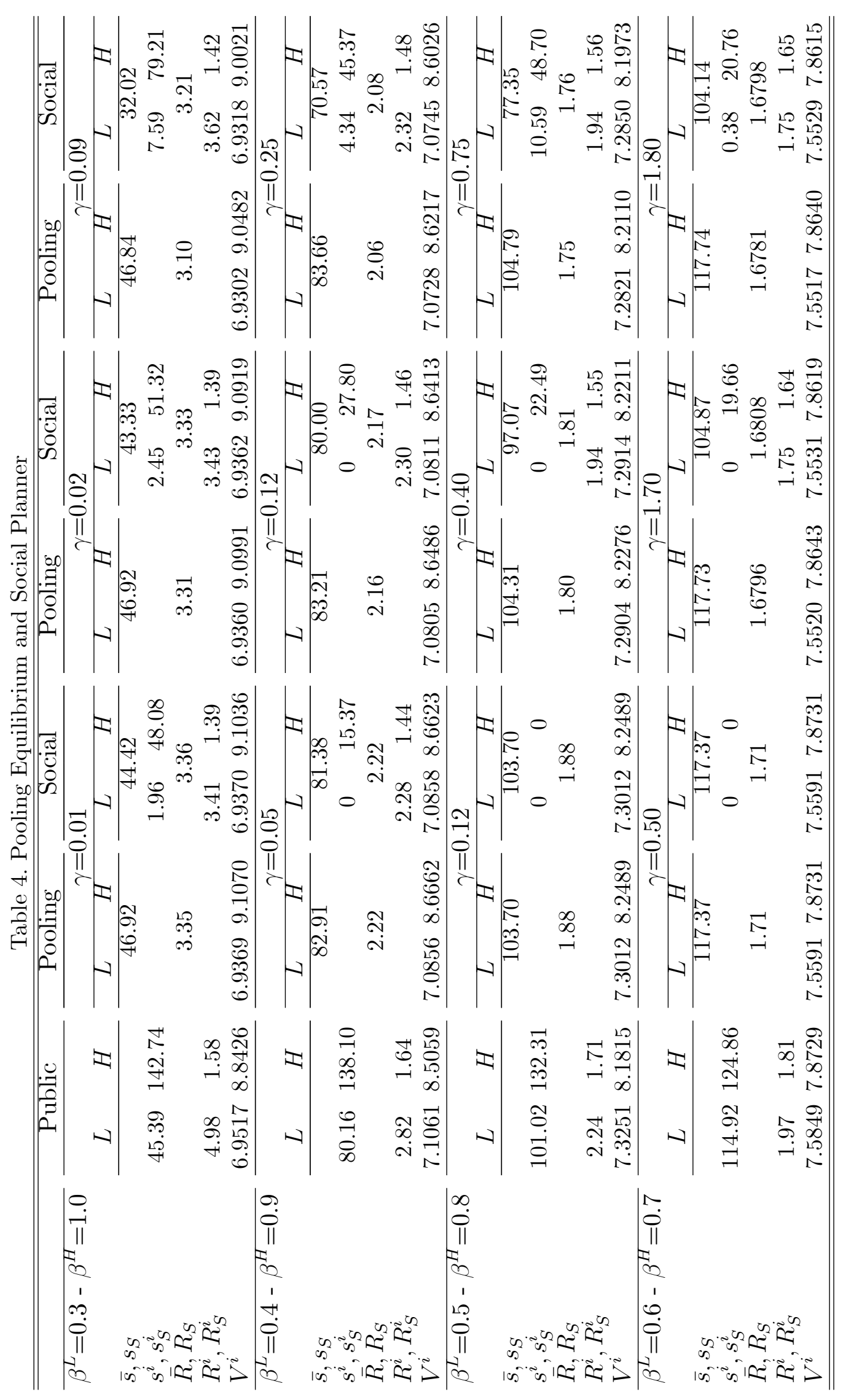


when the difference between the rates of time preference $\beta^{L}$ and $\beta^{H}$ is not big and if the number of type $H$ agents is small with respect to the number of type $L$ agents (when $\beta^{L}=0.4$ and $\beta^{H}=0.9$ if $\gamma \leq 0.12$, when $\beta^{L}=0.5$ and $\beta^{H}=0.8$ if $\gamma \leq 0.40$ and when $\beta^{L}=0.6$ and $\beta^{H}=0.7$ if $\left.\gamma \leq 1.70\right)$. Then in this scenario we can distinguish two different possibilities.

Type $H$ individuals have a residual demand for annuity

$$
s_{S}^{H}>0
$$

and then the utility of individuals of group $L$ is higher in case of mandatory social security than in case of pooling equilibrium because $R\left(\mathbf{h}_{\mathbf{S}}\right)>R(\overline{\mathbf{h}})$

- when the difference between the rates of time preference $\beta^{L}$ and $\beta^{H}$ is relatively big even if the number of type $H$ agents is very small with respect to the number of type $L$ agents (when $\beta^{L}=0.4$ and $\beta^{H}=0.9$ even if $\gamma \leq 0.05$ - with $\gamma=0.05$ we have $\left.s_{S}^{H}=15.37\right)$

- when the difference between the rates of time preference $\beta^{L}$ and $\beta^{H}$ is relatively small or small if the number of type $H$ agents is not very small with respect to the number of type $L$ agents (when $\beta^{L}=0.5$ and $\beta^{H}=0.8$ if $0.12<\gamma \leq 0.40$ - with $\gamma=0.40$ we have $s_{S}^{H}=22.49$ - and when $\beta^{L}=0.6$ and $\beta^{H}=0.7$ if $0.50<\gamma \leq 1.70$ - with $\gamma=1.70$ we have $\left.s_{S}^{H}=19.66\right)$.

Type $H$ individuals don't have a residual demand for annuity

$$
s_{S}^{H}=0
$$

and then the utility of individuals of group $L$ is not higher in case of mandatory social security than in case of pooling equilibrium when the difference between the rates of time preference $\beta^{L}$ and $\beta^{H}$ is relatively small or small if the number of type $H$ agents is very small with respect to the number of type $L$ agents (when $\beta^{L}=0.5$ and $\beta^{H}=0.8$ if $\gamma \leq 0.12$ and when $\beta^{L}=0.6$ and $\beta^{H}=0.7$ if $\gamma \leq 0.50)$.

Therefore in the cases of a relatively small or small difference between the rates of time preference of two groups, if the value of $\gamma$ is not very small (when $\beta^{L}=0.5$ and $\beta^{H}=0.8$ if $\gamma \not 0.12$ and when $\beta^{L}=0.6$ and $\beta^{H}=0.7$ if $\gamma \$$ 0.50 ), then members of group $L$ prefer the public programme to the pooling equilibrium

$$
V^{L}\left(\mathbf{x}_{S}^{L}\right)>V^{L}(\overline{\mathbf{x}})
$$

In other words, there is room for Social Planner to implement a well-being improving policy for type $L$ agents if and only if individuals $L$ and $H$ are sufficiently heterogeneous. If individuals $L$ and $H$ are not sufficiently heterogeneous, then the number of type $H$ agents with respect to the number of type $L$ agents has to be large enough. 


\section{Conclusions}

The two important features whose combination distinguishes the model proposed from the previous literature are that the investment in health care $h$ is a choice variable (and the moral hazard problem occurs when this choice is unobservable) and that individuals are heterogeneous in time preference $\beta$ (and the adverse selection problem relies on $\beta$ being a private information). Hence both the adverse selection problem and the moral hazard problem arise from endogenous factors. Then this paper shows that when the information is private the annuity market is affected by inefficiencies and negative externalities both in case of separating equilibrium and in case of pooling equilibrium.

In case of separating equilibrium the fact that firms consider the possibility that individuals modify the investment in health care in the first period in response to separating contracts offered to them breeds an inefficiency and the presence of agents with higher rate of time preference (group $H$ ) exerts a negative externality on the other agents (group $L$ ). While the inefficiency caused by moral hazard is purely destructive, the negative externality caused by adverse selection is not purely destructive because it doesn't deteriorate the well-being of members of group $H$.

In case of pooling equilibrium the fact that firms consider the possibility that members of all groups modify the investment in health care in the first period in response to the pooling contract offered to them breeds an inefficiency and the presence of agents with higher rate of time preference (group $H$ ) exerts a negative externality on the other agents (group $L$ ) - the higher survival probability of type $H$ agents negatively affects the rate of return of the pooling contract. While the inefficiency caused by moral hazard is in principle purely destructive, the negative externality caused by adverse selection is not purely destructive because type $L$ agents are worse off than they would be in absence of private information, but type $H$ agents are not. Precisely for type $H$ agents the inefficiency caused by moral hazard is completely compensated by the fact that the rate of return of the pooling contract is higher than the rate of return of the separating contract with public information and then type $H$ agents are better off in case of private information than in case of public information.

Given the inefficiency due to moral hazard and the negative externality due to adverse selection the investigation of possible Pareto improving policies which the Social Planner can implement is interesting. In the last section of this work it is explored under which conditions a mandatory social security programme can have positive effects on welfare.

In case of separating equilibrium if individuals are not largely heterogeneous (if heterogeneity is large then the range of the relative size of two groups in which Social Planner can intervene is small, if heterogeneity is small then this range is large), both members of group $H$ and members of group $L$ prefer the compulsory public policy associated with the supplementary private insurance to the separating contracts and then the separating equilibrium is Pareto dominated by the public programme. 
In case of pooling equilibrium if individuals are sufficiently heterogeneous (if heterogeneity is relatively small or small then the number of type $H$ agents with respect to the number of type $L$ agents has to be large enough), then while individuals of group $H$ are better off in case of pooling equilibrium, individuals of group $L$ are better off in case of compulsory public policy associated with supplementary private insurance: the public programme improves the wellbeing of individuals affected by the inefficiency and the negative externality in a context of a pooling equilibrium.

Then we come to the conclusion that a separating equilibrium can be Pareto dominated by a public policy associated with a supplementary private insurance, while the well-being of individuals affected by the inefficiency and the negative externality in a context of a pooling equilibrium can be improved by such a policy.

\section{Appendix: The Non-Existence of a Rothschild-Stiglitz Equilibrium}

A Rothschild-Stiglitz equilibrium has problems of non-existence: (i) there cannot be a Rothschild-Stiglitz pooling equilibrium and (ii) consequently if there is a relatively small number of agents with higher survival probability there does not exist a Rothschild-Stiglitz equilibrium (see, e.g., Wilson (1977), Riley (1979b) and Eckstein, Eichenbaum and Peled (1985)).

There always exists some contract $A$ close to the pooling contract $F$ which, if offered, is preferred by members of group $L$ - individuals with lower survival probability $\pi^{L}$ - but not by members of group $H$ - individuals with higher survival probability $\pi^{H}$ (see figure 2).

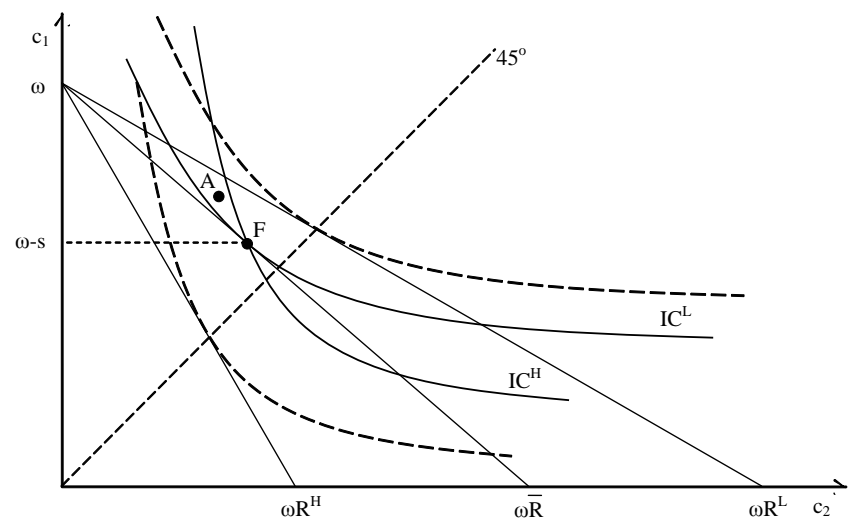

Figure 2. The Non-Existence of a Rothschild-Stiglitz Pooling Equilibrium

The contract $A$ will be exclusively bought by members of group $L$ and therefore if a firm offers this contract will earn non-negative profits. The second part of the definition of an equilibrium by Rothschild and Stiglitz (1976) states that there is no contract outside the equilibrium set that, if offered, will make a non-negative profit. Hence the Rothschild-Stiglitz pooling equilibrium does not exist. 
The pooling contract $F$ lies above both the indifference curve of type $L$ agent through point $E$ and the indifference curve of type $H$ agent through point $C$ (see figure 3 ). Then both members of group $L$ and members of group $H$ prefer the pooling contract $F$ to the separating contract $(E, C)$.

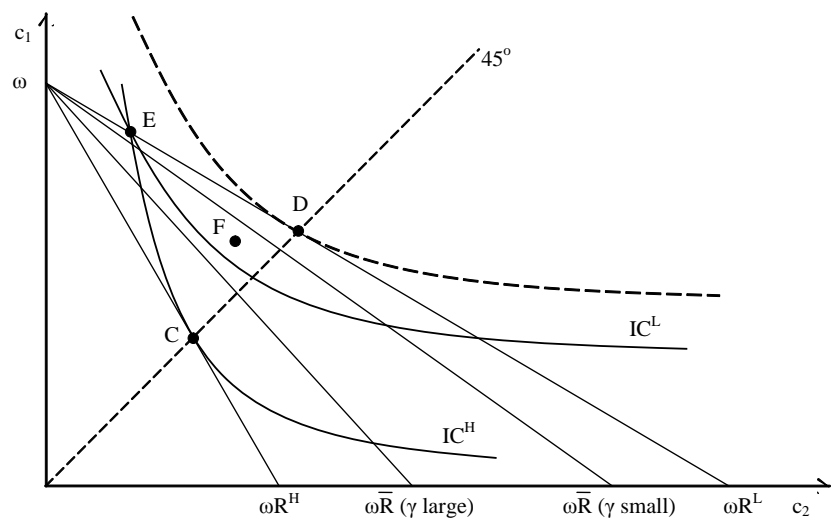

Figure 3. The Potentially Non-Existence of a Rothschild-Stiglitz Equilibrium

The rate of return of a pooling contract $\bar{R}=\frac{1+\gamma}{\pi^{L}+\gamma \pi^{H}}$ decreases monotonically in $\gamma$ (the relative size of the two groups $L$ and $H$ )

$$
\frac{\delta \bar{R}}{\delta \gamma}=\frac{\left(\pi^{L}-\pi^{H}\right)}{\left(\pi^{L}+\gamma \pi^{H}\right)^{2}}>0<0
$$

Therefore (i) if $\gamma$ is large then $\bar{R}$ is small and the pooling contract $F$ makes negative profits (the pooling contract $F$ is above the line $(\omega, \omega \bar{R})$ ) and (ii) if $\gamma$ is small then $\bar{R}$ is large and the pooling contract $F$ makes non-negative profits (the pooling contract $F$ is below the line $(\omega, \omega \bar{R})$ ).

The first part of the definition of an equilibrium by Rothschild and Stiglitz (1976) states that no contract in the equilibrium set makes negative expected profits. Hence the annuity supplying firms offer the pooling contract $F$ instead of the separating contract $(E, C)$ if $\gamma$ is small and therefore the RothschildStiglitz equilibrium does not exist.

\section{References}

ANDERBERG, D. (1999) Determining the mix of public and private provision of insurance by majority rule, European Journal of Political Economy 15(3), 417440 .

CORREA, H. (1983) A Conceptual Model of Health, in Research in Human Capital and Development: A Research Annual, Volume 3 - Heatlh and Development, I. Sirageldin, D. S. Salkever and A. Sorkin, eds. Greenwich, Connecticut: JAI Press. 
DAVIES, J. B., and P. KHUN (1992) Social security, longevity, and moral hazard, Journal of Public Economics 49(1), 91-106.

DIAMOND, P. A. (1977) A framework for social security analysis, Journal of Public Economics 8(3), 275-298.

ECKSTEIN, Z., M. EICHENBAUM and D. PELED (1985) Uncertain lifetimes and the welfare enhancing properties of annuity markets and social security, Journal of Public Economics 26(3), 303-326.

EPPLE, D. and R. E. ROMANO (1996) Public provision of private goods, Journal of Political Economy 104(1), 57-84.

FINKELSTEIN, A. (2002) When can partial public insurance produce Pareto improvement?, NBER Working Paper 9035.

GOUVEIA, M. (1997) Majority rule and the public provision of a private good, Public Choice 93(3), 221-224.

MAS-COLELL, A., M. D. WHINSTON and J. R. GREEN (1995) Microeconomic Theory, Oxford University Press: New York.

PAULY, M. V. (1974) Overinsurance and public provision of insurance: the roles of moral hazard and adverse selection, Quarterly Journal of Economics 88(1), 44-62.

RILEY, J. G. (1979a) Informational equilibrium, Econometrica 47(2), 331-359.

RILEY, J. G. (1979b) Noncooperative equilibrium and market signalling, American Economic Review 69(2), 303-307.

ROTHSCHILD, M., and J. E. STIGLITZR (1976) Equilibrium in competitive insurance markets: an essay on the economics of imperfect information, Quarterly Journal of Economics 90(4), 629-649.

SHAVELL, S. (1979) On moral hazard and insurance, Quarterly Journal of Economics 93(4), 541-562.

WILSOM, C. A. (1977) A model of insurance markets with incomplete information, Journal of Economic Theory 16(2), 167-207. 